\title{
EVOLUCIÓN DEL SECTOR TURÍSTICO EN LA PROVINCIA DE LEÓN (1985-2012)
}

\author{
Ana González Fernández \\ Área de Marketing \\ Departamento de Dirección y Economía de la Empresa \\ Universidad de León \\ e-mail: amgonf@unileon.es \\ Ana Rosa Pertejo Blanco \\ Área de Marketing \\ Departamento de Dirección y Economía de la Empresa \\ Universidad de León \\ e-mail: ana.pertejo@unileon.es
}

\begin{abstract}
1. Contexto turístico general - 2. Sector turístico de la provincia de León: 2.1. Oferta turística, 2.2. Demanda turística provincial - 3. Sector turístico de la ciudad de León: 3.1. Oferta turística, 3.2. Demanda turística, 3.3. Perfil sociodemográfico y hábitos comportamentales del turista de la ciudad de León: 3.3.1. Descripción del turista estival, 3.3.2. Descripción del turista del resto del año. Comparativa entre viajero de ocio y negocio - 3.4. Competitividad turística -4 . Política turística -5 . Conclusiones - Referencias
\end{abstract}

\section{Contexto turístico general}

El turismo es uno de los principales sectores económicos y fuente de ingresos en la balanza comercial española. Su carácter multisectorial constituye un indiscutible vector de desarrollo económico y social considerablemente con efectos dinamizadores aúnen época de crisis.

Un rápido análisis histórico de las macromagnitudes económicas y sociales en las tres últimas décadas permite observar aquellos aspectos con cierta trascendencia nacional que han conllevado importantes repercusiones en el desarrollo del sector en un destino cultural de interior, como es la provincia de León.

Los años ochenta constituyen un periodo convulso en lo que al consumidor turístico hace referencia. La rápida experiencia acumulada por los turistas entre los sesenta y los ochenta conlleva el surgimiento de un viajero experimentado y bien informado, que pone de manifiesto sus deseos de diferenciación mostrando cierto nivel de independencia.

Este nuevo contexto de la demanda induce a la oferta turística a definir estrategias de marketing diferenciadas enfocadas hacia distintos segmentos de mercado, lo que estimula el desarrollo de nuevas modalidades turísticas como el turismo cultural, urbano o rural, entre otros, así como la posibilidad de posicionar otras regiones, diferentes a las tradicionales de sol y playa, como destinos turísticos.

A partir de 1985 ocurren, además, una serie de acontecimientos que cambian el panorama turístico español. Surge el denominado turismo social, un programa de vacaciones dirigido a personas de la tercera edad a través del INSERSO cuyos efectos sobre la desestacio- 
nalización y la desconcentración geográfica son realmente importantes. En 1987 se alcanza un gran hito en el turismo español, se supera la barrera de 50 millones de visitantes, gracias a los avances tecnológicos y del transporte aéreo y por carretera.

La crisis de los años noventa provoca cierta incertidumbre en lo que al mercado emisor doméstico hace referencia, sin embargo, la inestabilidad de otros destinos competidores permite que el turismo receptivo mejore, consolidando España como destino. No obstante, la conducta de los viajeros pone de manifiesto que los gustos y motivaciones siguen cambiando mientras que la modalidad turística española por excelencia continúa siendo la de sol y playa, inmersa en la fase de madurez desde hace años. La política turística española decide, por fin, enfocarse también hacia tipologías como el turismo cultural, de naturaleza, o deportivo, tratando de captar nuevos segmentos de mercado.

El nuevo milenio avanza definitivamente hacia la desconcentración geográfica. En el año 2002 se produce una tímida recuperación y se vuelve a superar el record de 50 millones de turistas internacionales, sin embargo, la sobreoferta y el descenso del gasto de los turistas extranjeros en este país provoca que el volumen de ingresos reales y la rentabilidad empresarial no muestren los mismos indicios de recuperación por lo que se presta mayor atención al turismo interior. En los años sucesivos hasta el 2007 se sigue produciendo un incremento tanto de la demanda nacional como ligeramente de la extranjera, gracias a la recuperación de las economías de los países emisores, pero las excelentes previsiones auguradas para el 2008 se ven truncadas con la crisis económica internacional.

El turismo nacional hoy sufre los efectos de la crisis, no obstante, muestra una resistencia y unas consecuencias menos devastadoras que el resto de sectores económicos. De hecho, en 2012 España ocupa la cuarta posición en el ranking mundial de llegadas de turistas, tras Francia, EE.UU. y China (IET, 2013). Se puede apreciar, además, un cambio ascendente de la participación del turismo en la formación del PIB que alcanza nuevamente el $11 \% \mathrm{y}$, puede afirmarse que su repercusión puede tener todavía un recorrido ascendente en los próximos diez años (Figuerola Palomo, 2013). Recibe 57,7 millones de turistas internacionales con un gasto de 55.600 millones de euros, experimentando un crecimiento interanual del $5,7 \%$ y los turistas residentes realizan 146,7 millones de viajes dentro del territorio nacional, cifra similar a la del año anterior (IET, 2013).

La región de Castilla y León en 2012 se posiciona como la segunda comunidad autónoma después de Madrid en el ranking nacional, tanto respecto al número de viajeros como de pernoctaciones y es receptora del $11,6 \%$ de los viajes efectuados por los residentes españoles, ocupando el tercer lugar tras Andalucía $(18,2 \%)$ y Cataluña (15\%) (IET, 2013).

Con relación a las distintas modalidades turísticas que se pueden disfrutar en la comunidad, Castilla y León mantiene una posición de liderazgo en turismo rural y un gran potencial en las modalidades de turismo cultural, idiomático, enogastronómico, religioso, congresual, ornitológico y micológico.

La provincia de León, en concreto, ocupa a su vez el tercer puesto dentro de la comunidad autónoma en cuanto al número de turistas recibidos y de pernoctaciones, siendo por lo tanto uno de los principales destinos dentro de la región. Además, es la provincia con mayor número de establecimientos hoteleros, el 20,5\% de la Comunidad Autónoma y la que más plazas oferta, el 18,5\% (INE, 2013).

El presente capítulo analiza pormenorizadamente la evolución del mercado turístico tanto en la provincia leonesa como en la ciudad de León, a lo largo de las tres últimas décadas.

\section{Sec tor tunístico de la provincia de León}

La evolución del sector turístico en la provincia de León en el último cuarto de siglo es en términos generales positiva y constante. A continuación se realiza un análisis detallado del mercado turístico tanto desde la perspectiva de la oferta como de la demanda. 


\subsection{Oferta tuństica}

El ritmo de crecimiento de la oferta de establecimientos turísticos de la provincia de León desde 1985 hasta la actualidad es relativamente constante, aunque totalmente desigual respecto a las diferentes modalidades de alojamiento. Con la finalidad de poder realizar un análisis exhaustivo, se va a revisar la evolución de cada una de las categorías de alojamiento por separado durante dicho periodo.

La evolución de los hoteles (estrellas oro), modalidad alojativa por excelencia es positiva, ya que el incremento interanual desde 1985 hasta 2012 es del $4.59 \%$ en el caso de los establecimientos y del $3,23 \%$ en el de las plazas. Destaca el crecimiento concretamente de la década de los noventa ya que existen dos saltos cuantitativos importantes entre los años 91-93 y 98-2001. El año 2003 alcanza el mayor volumen de todo el periodo analizado establecimientos, 60 establecimientos que ofertan 4.837 plazas. A partir de dicha fecha disminuye paulatinamente como consecuencia del descenso del número de hoteles de categoría media y baja; no obstante, en los últimos cinco años se observa una tendencia en general ascendente.

Si se realiza una revisión más exhaustiva de los datos en función de las categorías de los hoteles, se puede observar que la modalidad de cinco estrellas en esta provincia es escasa, ya que existe un único establecimiento, el Parador de San Marcos. En el siguiente nivel los hoteles de cuatro estrellas experimentan un incremento importante, en el año 1985 existía un solo establecimiento mientras que en el 2012 hay dieciséis, pasando de ofertar 255 plazas a 2.365 plazas.

Los hoteles de tres estrellas también crecen a lo largo del periodo, pasando de 5 a 20 establecimientos, lo que representa respecto al número de plazas un salto de 697 a 1.362. Dicho incremento tiene su momento álgido en el año 2003, sin embargo, en el 2004 se produce un reajuste de la oferta de esta categoría hotelera que baja a 15 hoteles con 989 plazas, incrementándose de manera constante desde entonces hasta la actualidad.

Respecto a los hoteles de una y dos estrellas, evolucionan de diferente modo. La oferta de hoteles de dos estrellas crece hasta el 2001, año en el que comienza un cambio de tendencia, mientras que los hoteles de una estrella sufren un decremento prácticamente continuo durante todo el periodo analizado.

En términos generales se está incrementando principalmente la oferta hotelera de categoría media/alta, lo que pone de manifiesto una apuesta por la calidad en el sector del alojamiento en León.

\section{Gráfico 1}

Evolución de la hotelería por categorías en León (1985-2012). Establecimientos

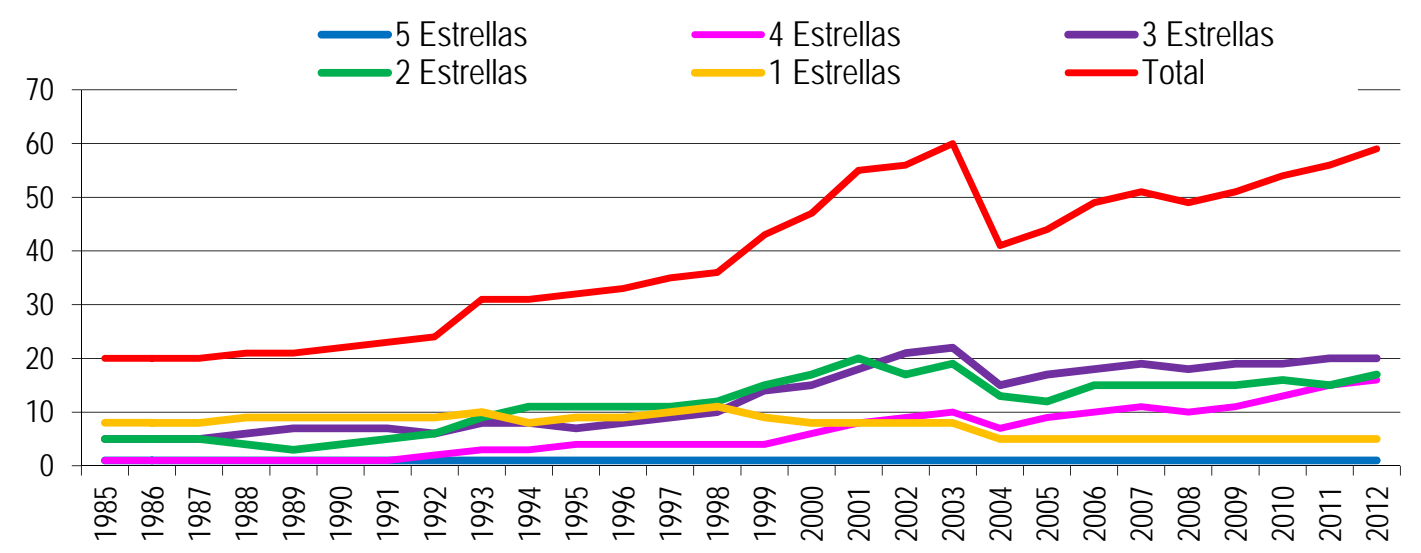


Evolución de la hotelería por categorías en León (1985-2012). Plazas

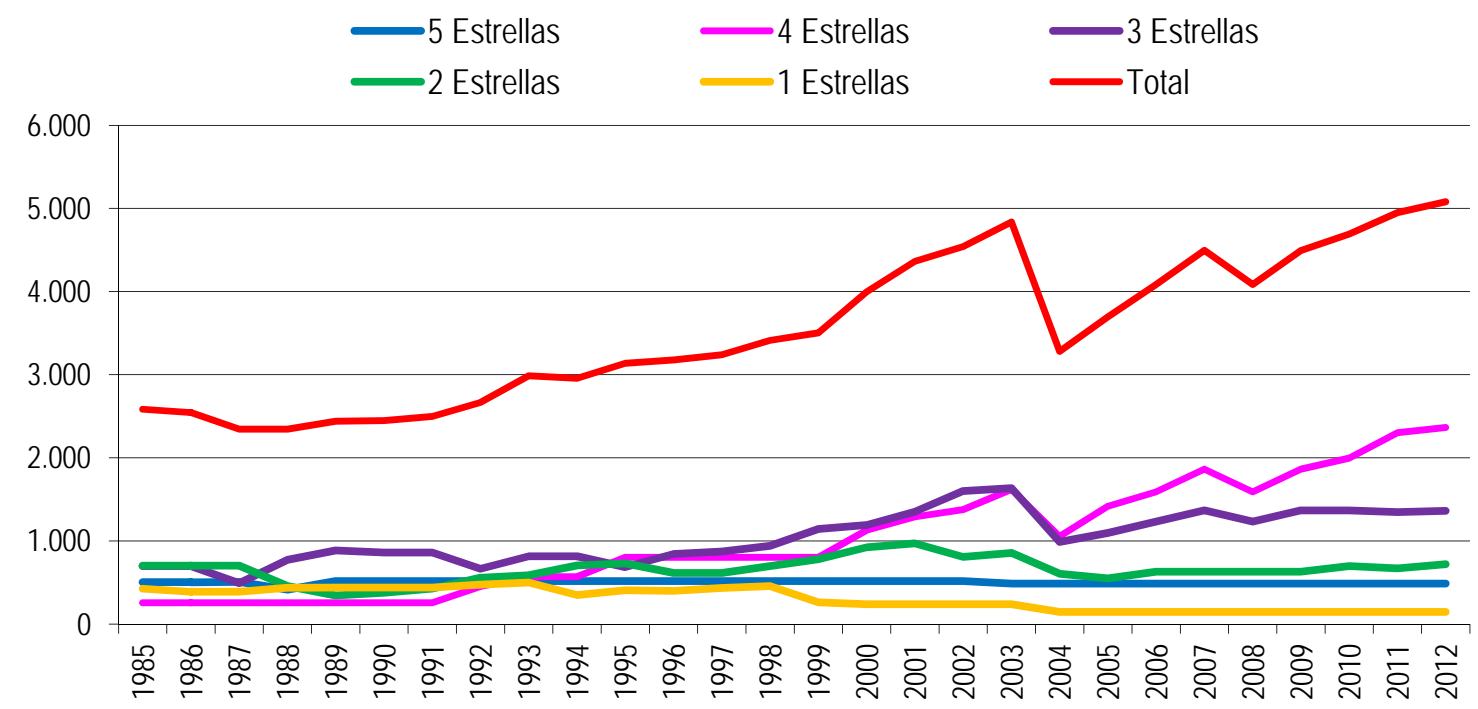

Fuente: Elaboración propia a partir de datos de la Junta de Castilla y León (1986-2013).

La oferta de hostales (estrellas plata) y pensiones desciende considerablemente a lo largo del periodo analizado. En 1985 la modalidad de hostales era posiblemente la más abundante, 113 establecimientos que ofrecían 3.178 plazas, sin embargo, paulatinamente han disminuido. En 2012 existen 82 hostales con 2.022 plazas, es decir, ha decrecido un $27 \%$ el número de hostales y cerca del $36 \%$ el volumen de plazas. En cuanto a las pensiones, en 1994, primer año del que se dispone de datos estadísticos, había 139 pensiones que ofrecían 1.781 plazas, dieciocho años más tarde, existen 103 establecimientos que ofertan 1.297 plazas. A pesar de su abundancia, la tendencia también es decreciente, casi un $26 \%$ en el volumen de establecimientos y un $27 \%$ en el de plazas.
En el año 2004, surgen nuevas categorías relacionadas con la hotelería, los hotelesresidencia y hoteles-apartamento que se disgregan de la categoría general de hoteles, cuya oferta en valores absolutos se mantiene prácticamente constante desde su inicio. Surgen además los hostales-residencia, cuya oferta se incrementa ligeramente. Finalmente, también en el mismo año aparece en la provincia una nueva categoría, los moteles, cuya presencia es prácticamente anecdótica, ya que sólo existe uno desde sus orígenes. En conjunto, se puede afirmar que dichas modalidades intermedias son muy escasas en la provincia.

Otras categorías como las fondas y casas de huéspedes, considerablemente numerosas respecto a la oferta de plazas en los años ochenta, desaparecen a comienzos de los noventa. 


\section{Gráfico 2}

Evolución de los establecimientos de hostelería en León (1985-2012)

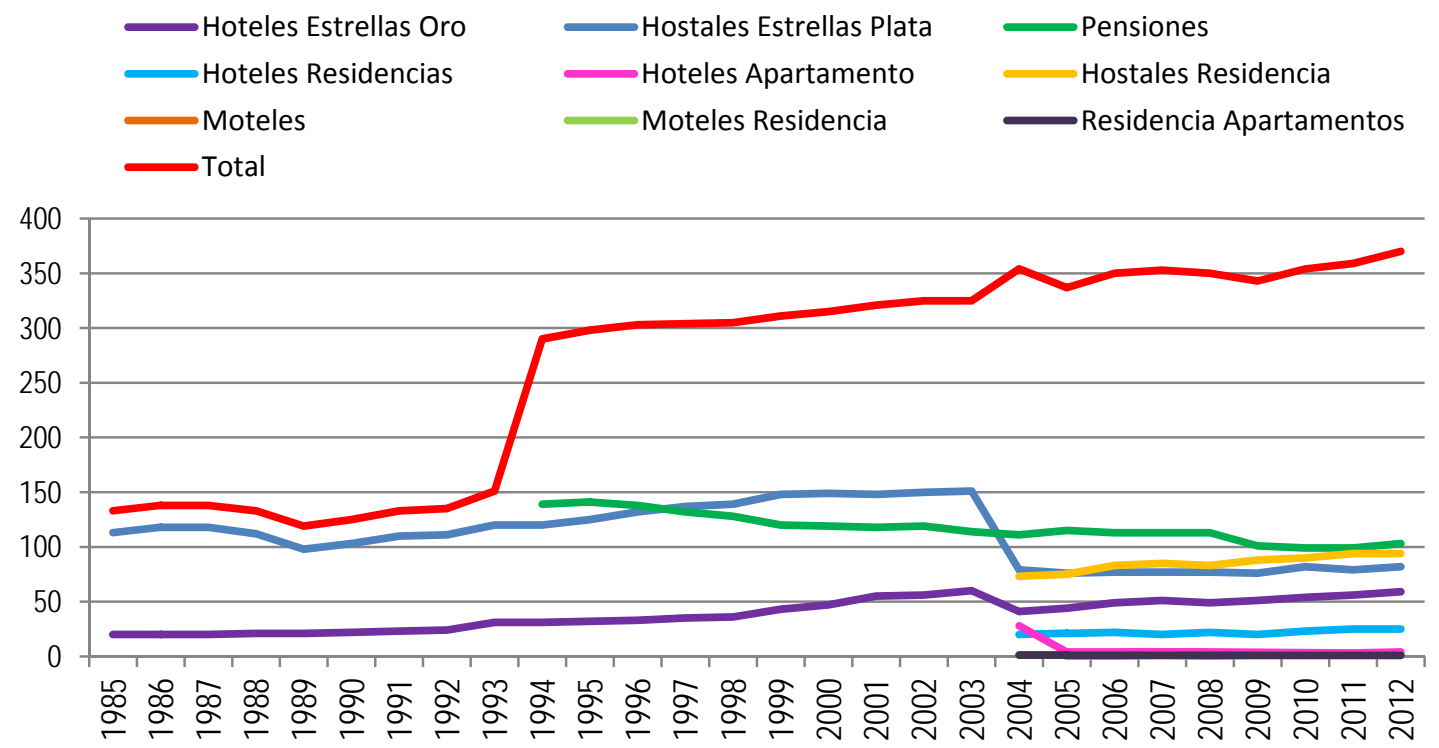

Evolución de las plazas de hostelería en León (1985-2012)

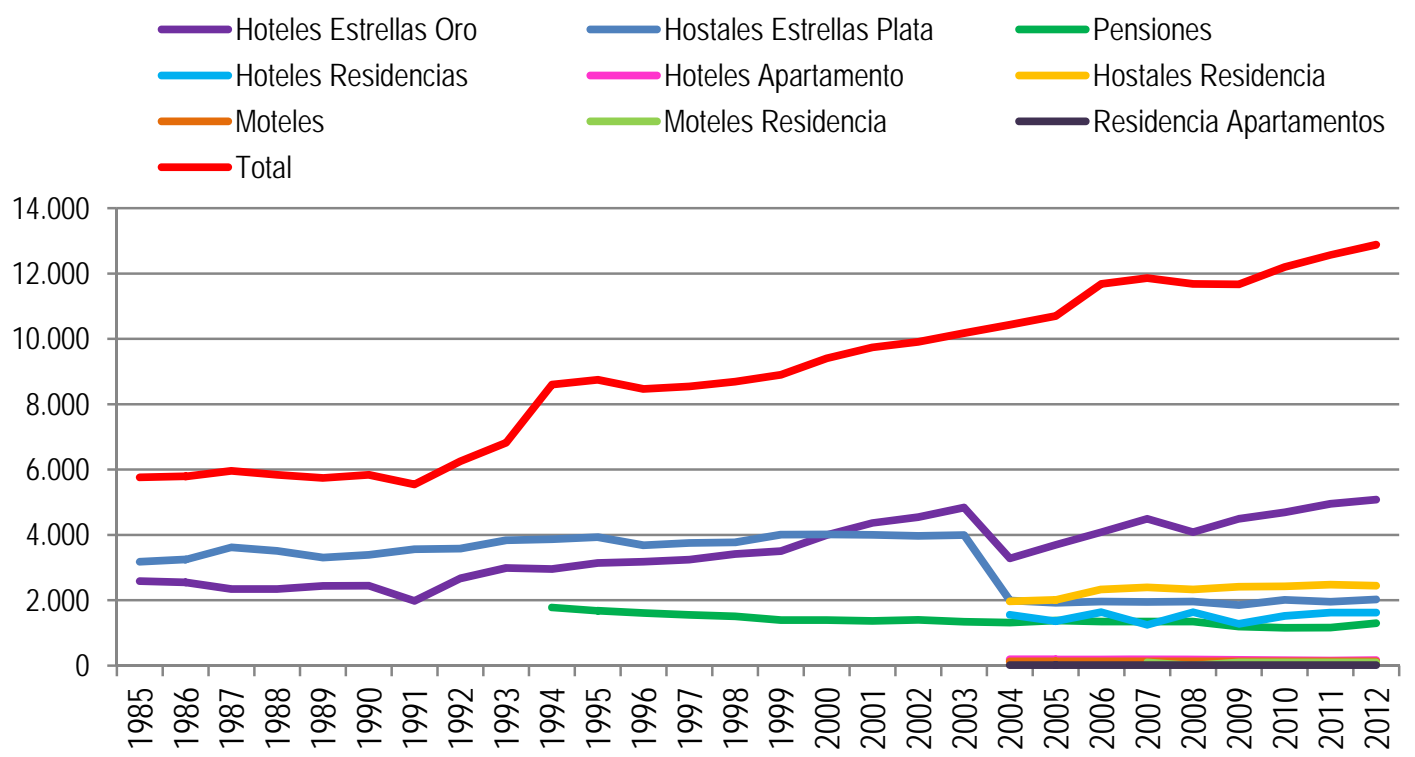

Fuente: Elaboración propia a partir de datos de la Junta de Castilla y León (1986-2013).

En cuanto al personal ocupado en establecimientos hosteleros, la Encuesta de Ocupación
Hotelera del INE ofrece datos desde el año 2003 de hostales y hoteles en todas sus 
categorías. Se puede observar que en las categorías de cuatro y tres estrellas oro el número de personas empleadas aumenta considerablemente, mientras que en el resto se mantiene o baja, como en el caso de una estrella de plata.
En su conjunto, la media anual de personas empleadas en hoteles y hostales pasa de 998 en 2003 a 1161 en 2012, siendo las categorías de cuatro y tres estrellas las que más personal ocupan en 2012, concretamente el 60\% del total.

\section{Gráfico 3}

Personal ocupado en establecimientos hoteleros en la provincia de León (medias anuales). 2003-2012

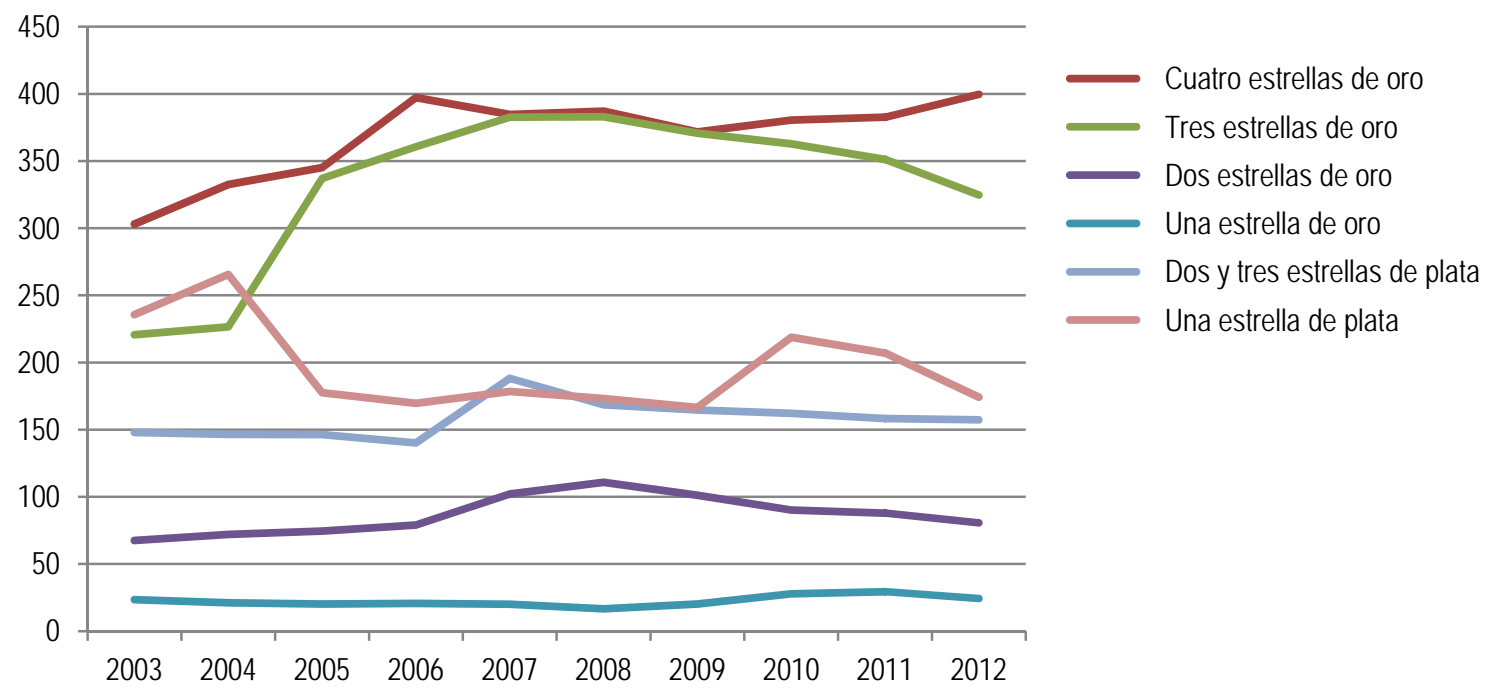

Fuente: Elaboración propia a partir de datos del INE (2004-2013).

Existen además los denominados hasta el año 1993 apartamentos turísticos (a partir de entonces apartamentos), entre los que se pueden diferenciar tres categorías, de una a tres llaves, los campamentos turísticos (campings), los campamentos y albergues juveniles $y$, finalmente, los alojamientos de turismo rural, modalidad considerablemente reciente de elevada relevancia en la provincia.

La evolución experimentada de 1994 al $2012^{1}$ por los apartamentos es considerablemente positiva, aunque el número de establecimientos no es muy elevado, pasa de 4 a 29. En los

\footnotetext{
1 Se lleva a cabo un análisis de la evolución desde 1994 al 2012, puesto que se trata del periodo metodológicamente comparable, ya que de 1987 al 1994 , existen gaps en el volumen de establecimientos difícilmente justificables.
}

últimos dieciocho años se ha producido un incremento medio interanual del $17 \%$. El volumen de plazas ofertadas sigue la misma tendencia, crece interanualmente el $14 \%$, de 106 a 576 plazas. Realmente es en el 2012 , cuando se produce un salto cuantitativo importante, de 16 a 29 establecimientos. 


\section{Gráfico 4}

Evolución de los apartamentos en León (1994-2012). Establecimientos y plazas
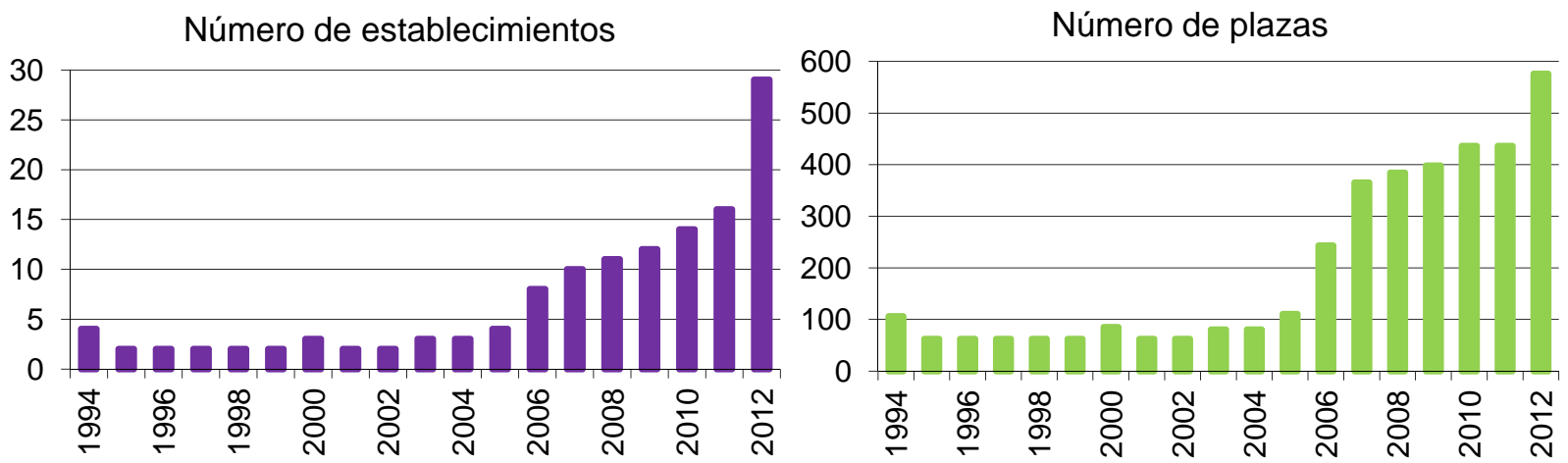

Fuente: Elaboración propia a partir de datos de la Junta de Castilla y León (1995-2013).

Una de las tipologías más extendidas en todo el territorio nacional y, como no podía ser de otro modo, también en el leonés, son los campamentos turísticos (campings), las categorías existentes son lujo-primera, segunda y tercera. En esta región la categoría más abundante es la segunda con 37 campings que ofertan 9.657 plazas, cuya evolución positiva a lo largo de todo el periodo analizado conlleva un incremento medio interanual próximo al 5\%. La opción de mayor calidad es la que ofrece menor número de campings, sólo 3 que ofertan 1.135 plazas, incrementándose éstas últimas a lo largo de estos años un 2,2\%, mientras que los campings de menor categoría han disminuido hasta su extinción.

\section{Gráfico 5}

\section{Evolución de los campings en León (1985-2012). Establecimientos y plazas}
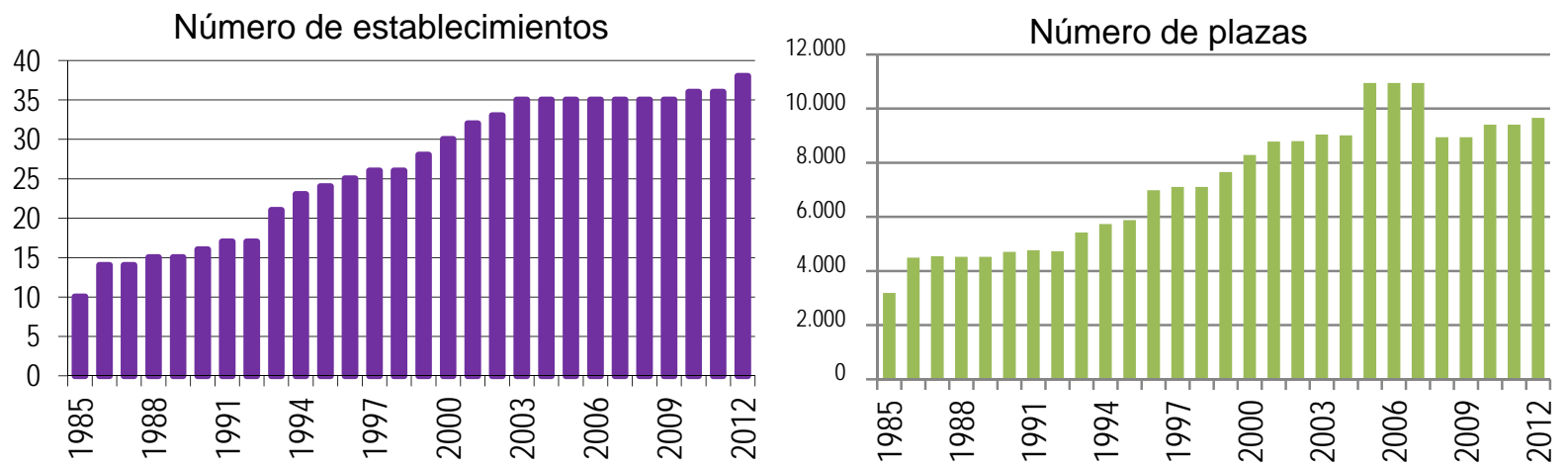

Fuente: Elaboración propia a partir de datos de la Junta de Castilla y León (1995-2013).

En 1988, los campamentos y albergues ${ }^{2}$ comienzan a ofrecer alojamiento a la juventud,

\footnotetext{
2 No existen todavía datos disponibles del año 2012 sobre campamentos y albergues juveniles.
}

estos últimos de manera temporal como residencias juveniles. En dicho año existe un campamento que ofrece 200 plazas y dos albergues temporales con 160 plazas. En el año 1990 aparece un primer albergue 
permanente de pequeña capacidad (45 plazas) y se incrementa considerablemente el número de plazas de campamentos al abrir dos (705 plazas). A partir de entonces y hasta 2004 , año en el que se registra el número máximo de plazas, el volumen aumenta considerablemente. A partir de ese momento, los albergues temporales fluctúan de un año a otro tanto en plazas como en establecimientos, y los campamentos aumentan muy poco su oferta.

\section{Gráfico 6}

\section{Evolución de los campamentos y albergues juveniles en León (1988-2011)}
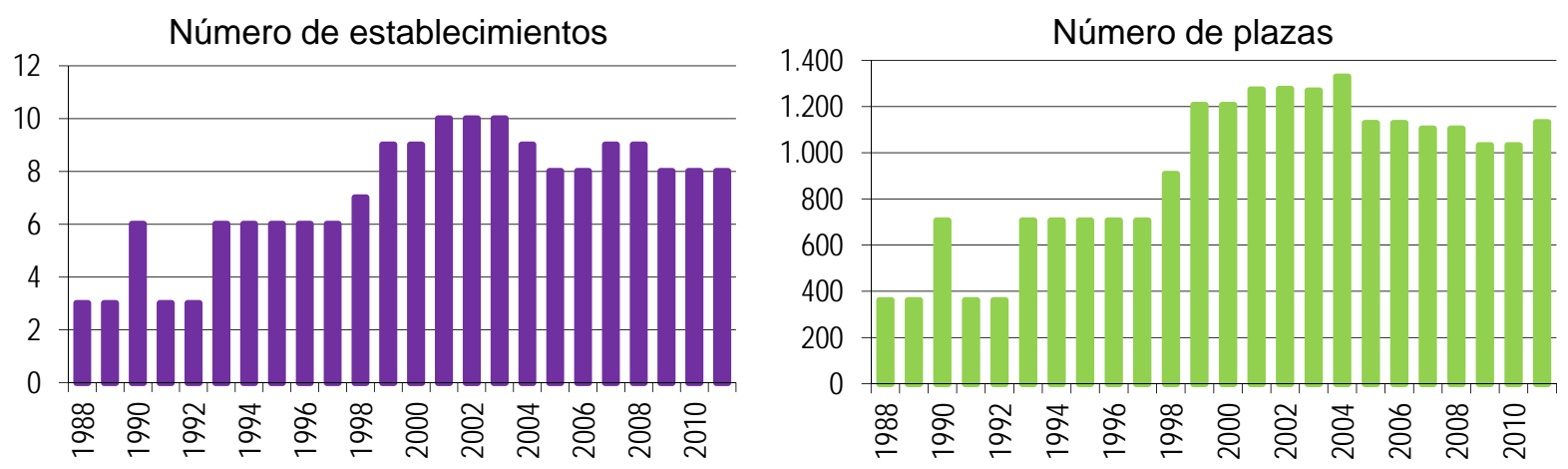

Fuente: Elaboración propia a partir de datos de la Junta de Castilla y León (1986-2012).

Finalmente, el turismo rural merece una mención especial dentro del sector turístico en la provincia de León, dado su auge respecto al conjunto español. Su andadura comienza con el programa europeo Leader, cuya finalidad era apoyar el desarrollo rural, la formación y las Pymes y, dentro de los sectores a impulsar, el turismo y la artesanía, entre otros. Dicho programa vino acompañado de otros como el PRODER, MINER, etc.

Los promotores iniciales de esta tipología turística comenzaron a desarrollar sus proyectos en el ámbito rural sin apenas contacto entre ellos, es en la feria internacional de turismo FITUR de 1995, cuando constataron la necesidad de agruparse con la finalidad de abordar acciones de carácter conjunto y solicitar ayudas que individualmente tenían restringidas, por este motivo se crea la Asociación de Empresarios de Turismo Rural (ALETUR).

Las categorías de alojamiento de turismo rural en la provincia vienen determinadas desde el RD 84/1995 establecido por la Junta de Castilla y León y son las siguientes: casa rural de alojamiento compartido (CRAC), casa rural de alquiler completo (CRA), posadas (PO) y centros de turismo rural (CTR).

En el año 1994 existen solo 7 establecimientos que ofrecen 90 plazas, dieciocho años más tarde 553 establecimientos ofertan 4.808 plazas. La modalidad más abundante y que más ha crecido a lo largo de este periodo es la casa rural de alquiler completo, posiblemente debido a la facilidad que conlleva gestionar dicho alojamiento ya que no necesita personal disponible de manera continua para atender a los clientes, sólo mantenimiento y limpieza de la casa (incremento interanual medio del número de establecimientos el $37 \%$ y el $40 \%$ en las plazas). A continuación se sitúan los centros de turismo rural, cuyo volumen de alojamientos es considerablemente abundante y el de plazas, numeroso, seguidos por la casa rural de alojamiento compartido, modalidad en la que el propietario comparte la casa con sus clientes. Por último están las posadas, alojamientos de interés histórico, cuyo número es sustancialmente inferior. 
Gráfico 7

Evolución de los alojamientos de turismo rural en León (1994-2012). Establecimientos y plazas

Número de establecimientos

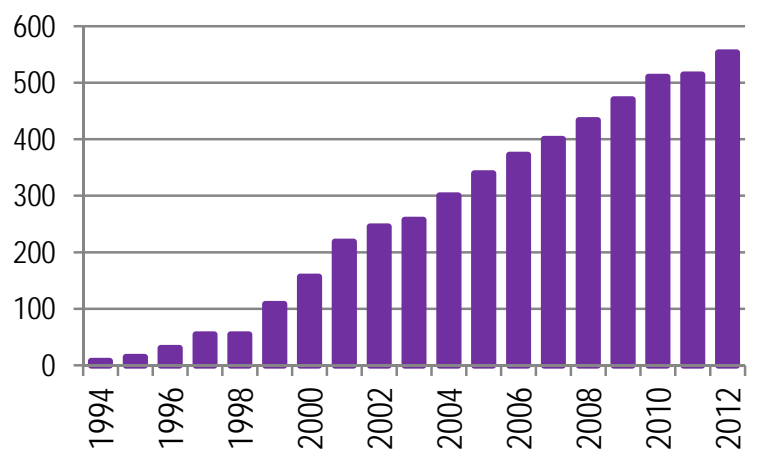

Número de plazas

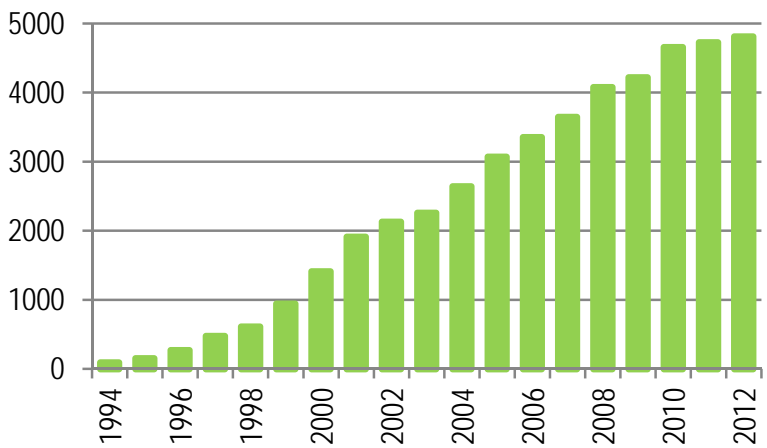

Fuente: Elaboración propia a partir de datos de la Junta de Castilla y León (1995-2013).

En cuanto al empleo generado por el conjunto de estas tipologías de alojamiento en la provincia de León, evoluciona de acuerdo al número de establecimientos. La media anual de personal ocupado en hoteles y hostales y alojamientos de turismo rural, ha aumentado respectivamente el $16 \%$ y $79 \%$ entre 2003 y 2012, categorías que engloban en 2012 el 95\% del personal.

\section{Gráfico 8}

\section{Personal ocupado en la provincia de León, 2003-2012 (medias anuales)}

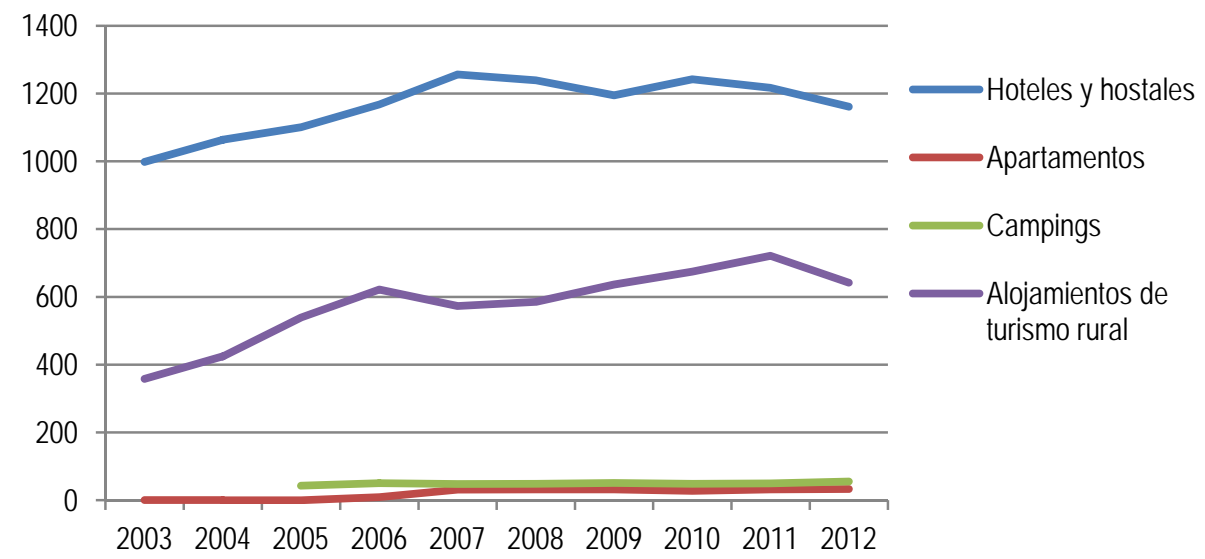

Fuente: Elaboración propia a partir de datos del INE (2004-2013).

Finalmente, el ratio del grado de ocupación en la provincia de León se ha mantenido considerablemente constante a lo largo de los últimos once años con pequeños repuntes en el año 2004 y 2007 y una tendencia ligeramente descendente a partir de dicho año. El nivel de ocupación provincial es durante este periodo ligeramente inferior al de Castilla y León y sustancialmente menor que el español. 


\section{Gráfico 9}

Evolución del grado de ocupación (1999-2012)

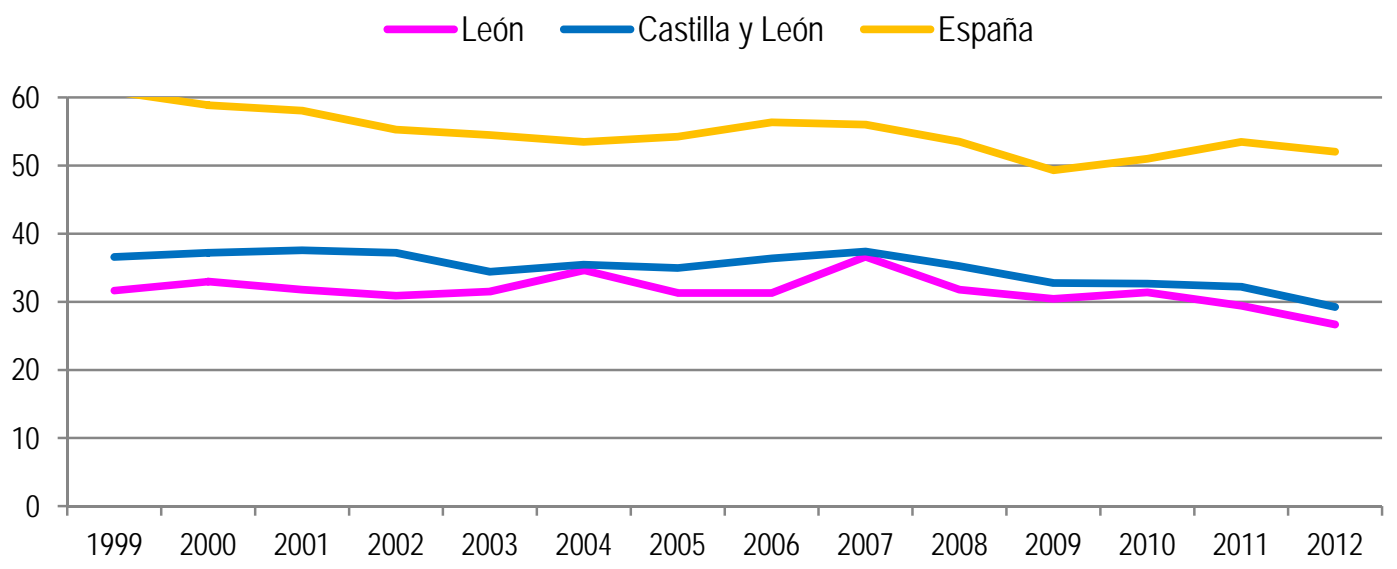

Fuente: Elaboración propia a partir de datos del INE (2000-2013).

El sector de distribución en la provincia de León en el año 1987 es prácticamente anecdótico (17 empresas minoristas), mientras que en la actualidad la oferta alcanza 102 empresas, de las cuáles el $74,51 \%$ son minoristas y el resto mayoristas-minoristas. Desde el año 2007, se recoge además información sobre las empresas de distribución on-line, aunque por el momento representan un porcentaje pequeño, en dicho año suponían el $1 \%$ y hoy casi alcanzan el $7 \%$. Respecto al peso de este sector en la provincia frente a la comunidad autónoma, no ha superado desde sus inicios el $21 \%$, disminuyendo ligeramente en 2012.

\section{Gráfico 10}

Evolución de las empresas de distribución turística (1999-2012)

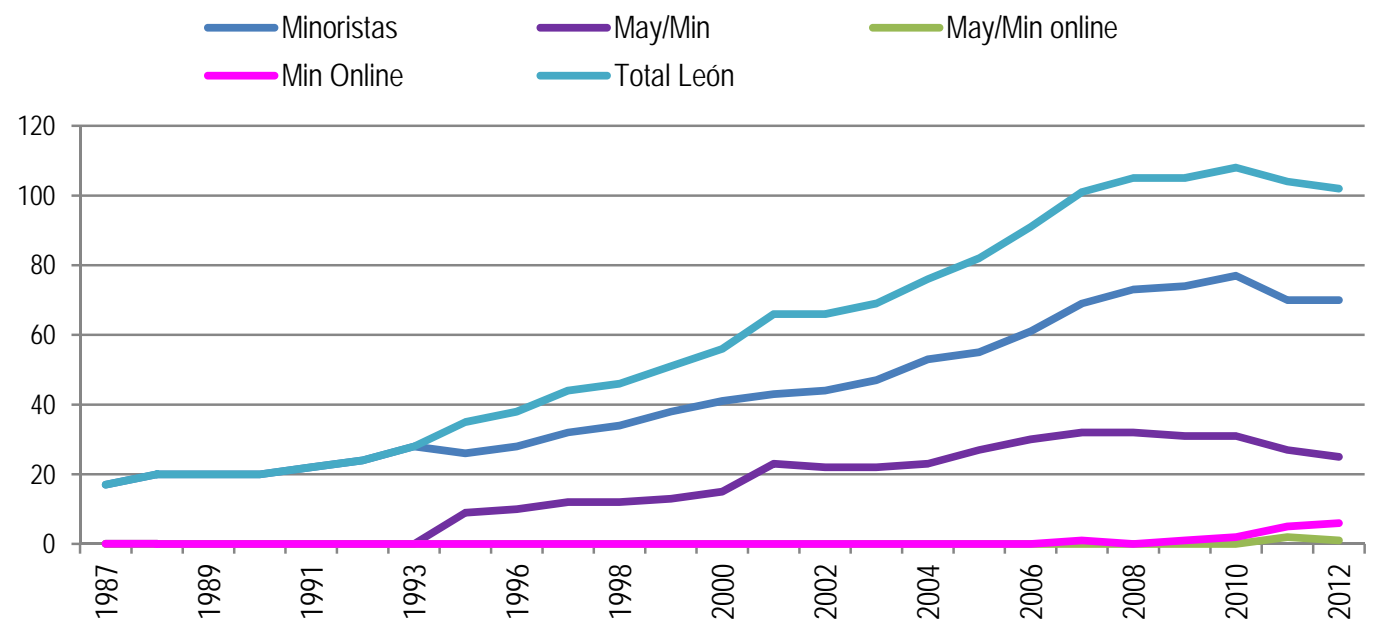

Fuente: Elaboración propia a partir de datos de la Junta de Castilla y León (1986-2013). 
El sector de restauración en la provincia experimenta una evolución diferente en restaurantes y cafeterías. Los restaurantes han seguido una tendencia de crecimiento constante, con un incremento interanual medio del 3,6\% en el número de establecimientos y

\section{Gráfico 11}

Evolución de los restaurantes en León (1985-2012)

Número de establecimientos

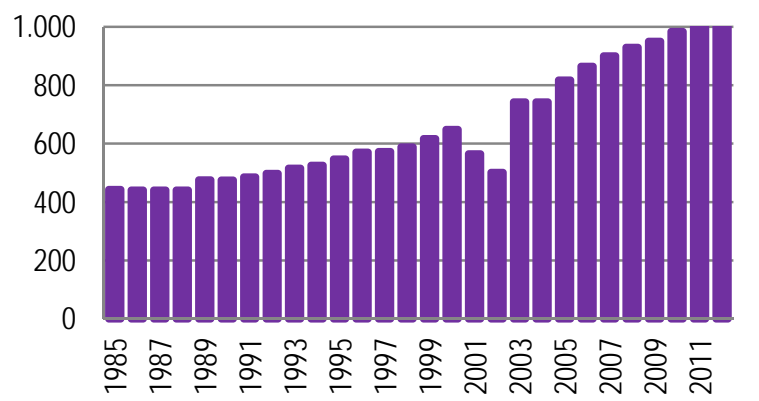

del 4,6\% en el número de plazas. Pasa de 442 establecimientos que ofrecen 25.199 plazas en el año 1985 a 1.035 establecimientos con 72.763 plazas en el año 2012, lo que supone un incremento global desde 1985 del 134\% y $189 \%$ respectivamente.

Fuente: Elaboración propia a partir de datos de la Junta de Castilla y León (1986-2013).

El crecimiento las cafeterías en los primeros diez años analizados es importante, posteriormente las cifras se mantienen constantes hasta el año 2012. El número de establecimientos pasa de 155 a 280 y el número de plazas aumenta de 8797 a 15280 entre 1985 y 2012, respondiendo a un

\section{Gráfico 12}

\section{Evolución de las cafeterías en León (1985-2012)}

Número de establecimientos

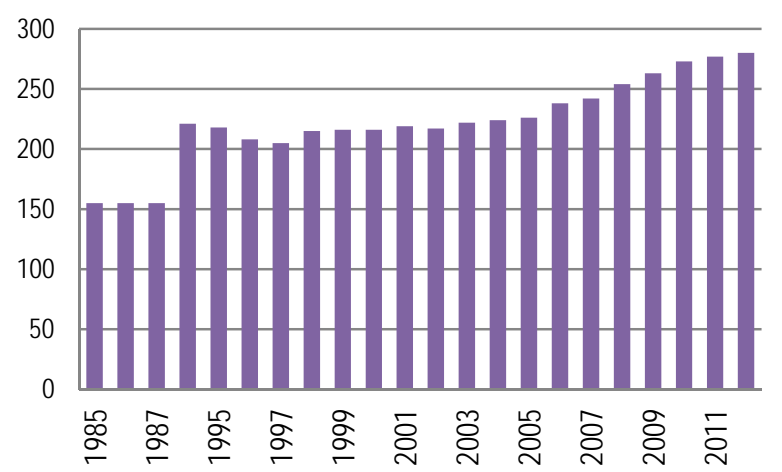

incremento interanual medio del 3,19\% y del $3,02 \%$ respectivamente. No obstante, el incremento interanual medio de la última década es del $2,28 \%$ en el caso de los establecimientos y solamente del $0,63 \%$ en el de las plazas.

Fuente: Elaboración propia a partir de datos de la Junta de Castilla y León (1986-2013). 


\subsection{Demanda turística provincial}

La demanda turística de León es creciente en términos generales durante todo el periodo analizado, ya que ha pasado de un volumen de viajeros en 1985 de 314.801 a 651.114 en el año 2012, habiéndose producido un incremento medio anual del $3.46 \%$ y un aumento total próximo al $107 \%$. No obstante, dicho crecimiento no se ha distribuido por igual a lo largo de todas las décadas, se puede observar que es considerablemente más intenso en la década de los noventa, en la que prácticamente se ha duplicado el número de viajeros recibidos en la provincia.

\section{Gráfico 13}

\section{Evolución del número de viajeros (1985-2012)}

Esta tendencia se debe tanto a las visitas recibidas por los turistas nacionales, cuyo incremento interanual medio es del 3,3\%, así como al importante aumento de turistas extranjeros que alcanzó un incremento interanual medio superior al 10\%. Posiblemente la razón fundamental reside en que en los años ochenta apenas se podía considerar León como un destino para el turismo exterior, mientras que en la actualidad está alcanzando cierta notoriedad. Aun así, el número de visitantes extranjeros es sustancialmente inferior respecto al turismo de interior, en 1985 la provincia leonesa recibe 13.867 turistas de fuera de las fronteras nacionales y 300.934 turistas naciónales, alcanzando en 2012, 132.953 turistas extranjeros y 518.162 nacionales.

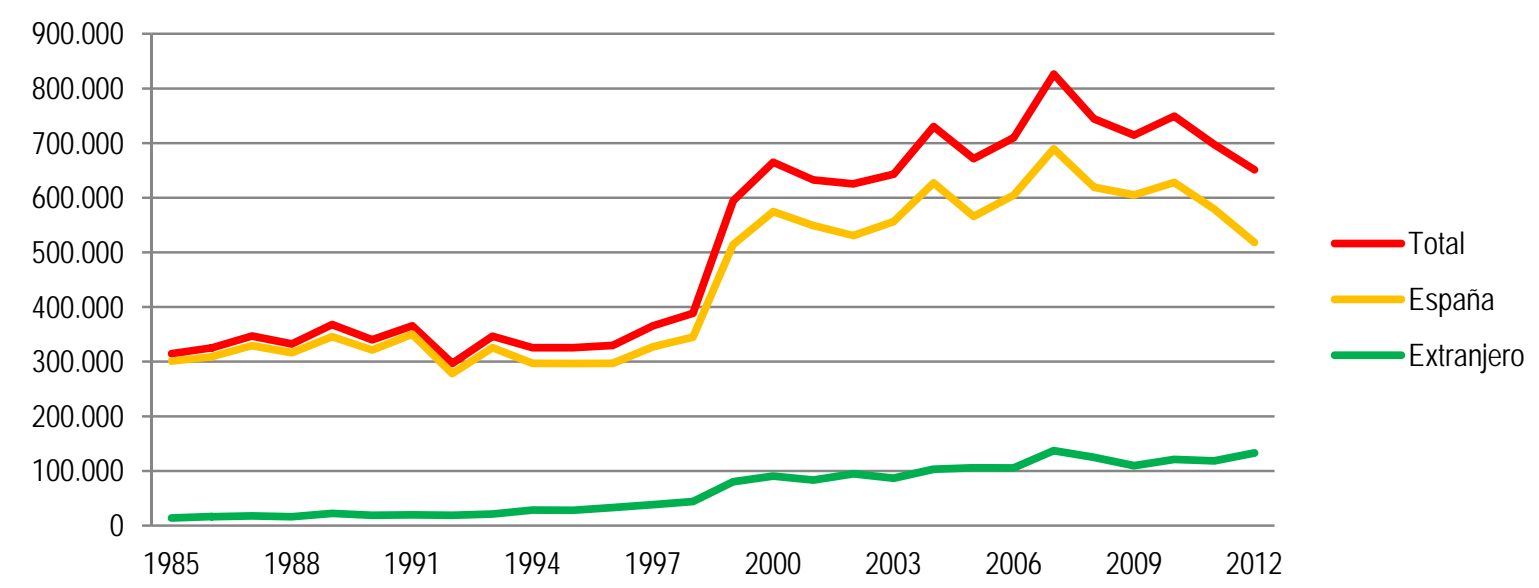

Fuente: Elaboración propia a partir de datos del INE(1986-2013).

Los viajeros españoles que visitan la provincia de León proceden en su mayor parte de zonas cercanas a la región, casi el $65 \%$ viene de las provincias pertenecientes a la propia comunidad autónoma seguido de Madrid, Galicia y Asturias.
Desde el año 2003 solo se han producido pequeñas variaciones a este respecto, la más destacable el incremento de viajeros procedentes del País Vasco que ha subido del $4,57 \%$ al $7,23 \%$. 


\section{Gráfico 14}

Distribución porcentual de los viajeros españoles a la provincia de León según su CCAA de origen (20032012)

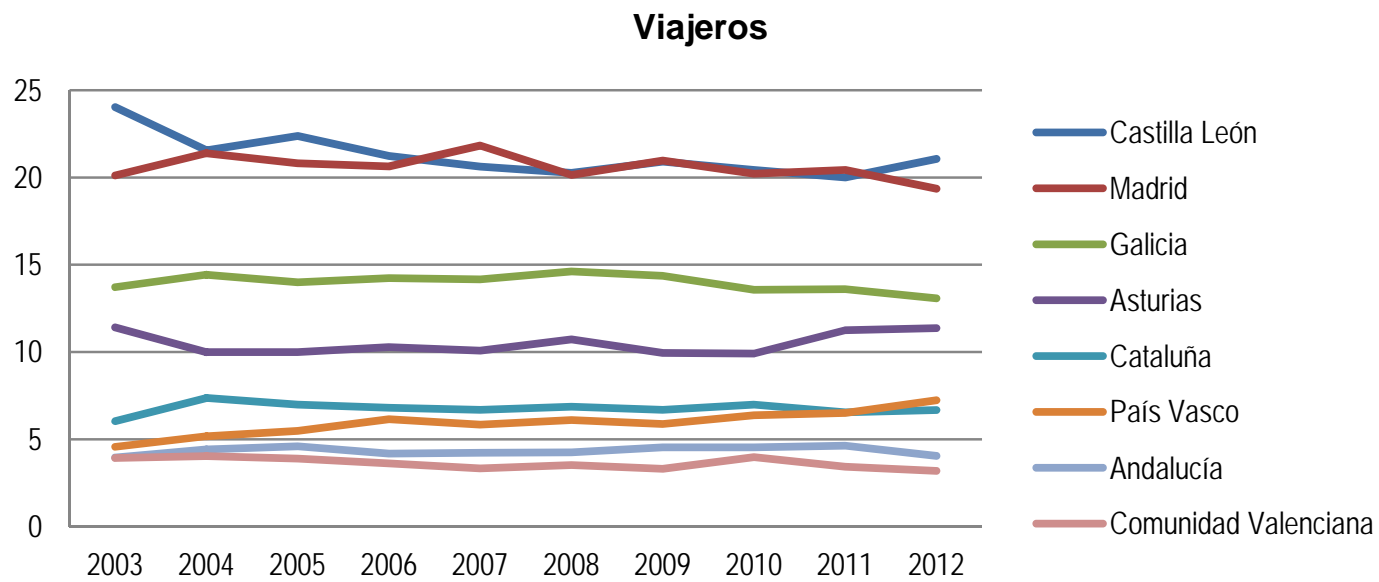

Fuente: Elaboración propia a partir de datos del INE (2004-2013)

El origen del turismo internacional desde 1985 hasta la actualidad es mayoritariamente europeo. El principal país emisor de turistas hacia la provincia de León durante todo el periodo analizado es Alemania, alternándose en el segundo puesto Francia y Reino Unido. A continuación se han ido relevando Portugal, EEUU e Italia. Concretamente en el 2012 el ranking emisor de turistas se sitúa en el siguiente orden: Alemania, Francia, Italia y EEUU.

\section{Gráfico 15}

Evolución del número de viajeros extranjeros por nacionalidad (1985-2012)

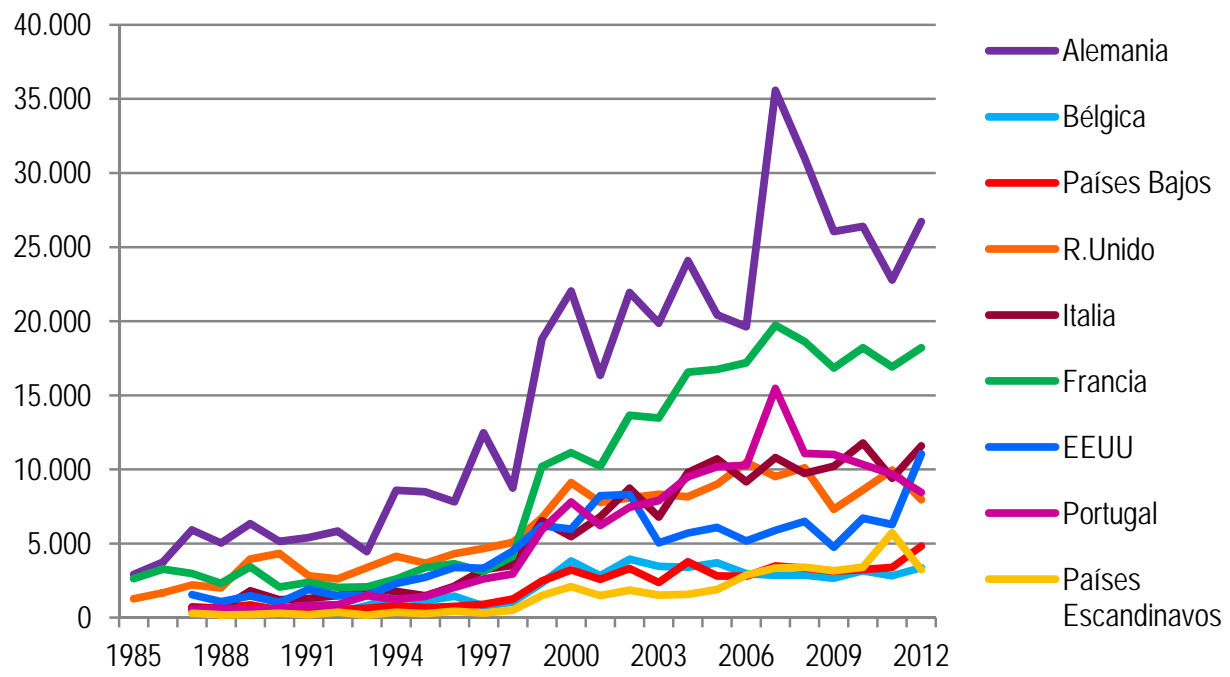

Fuente: Elaboración propia a partir de datos del INE (1986-2013). 
Con relación a las pernoctaciones, indicador de especial relevancia para el sector turístico, se ha de indicar que sigue una tendencia similar al número de viajeros. En 1985 el volumen de pernoctaciones es de 582.386, incrementándose de media a lo largo del periodo analizado aproximadamente un 3\% en 2012 alcanza 1.066.015 pernoctaciones. Durante la década de los noventa llega a un crecimiento del $75 \%$ superando cualquier expectativa, sin embargo en los últimos diez años el crecimiento se estanca debido en gran medida a la caída experimentada en el último año.
El volumen de pernoctaciones del turismo de interior es muy superior al extranjero. De hecho, en 1985 el número de pernoctaciones de turistas españoles es de 565.751 frente a los 16.634 turistas extranjeros, con tendencia positiva alcanzando los 889.859 turistas nacionales y 176.155 turistas internacionales en 2012. Nuevamente, el ritmo de crecimiento interanual a lo largo del periodo analizado es muy superior en el caso del turismo internacional (10.82\%), frente al nacional (2.47\%).

\section{Gráfico 16}

Evolución del número de pernoctaciones de turistas (1985-2012)

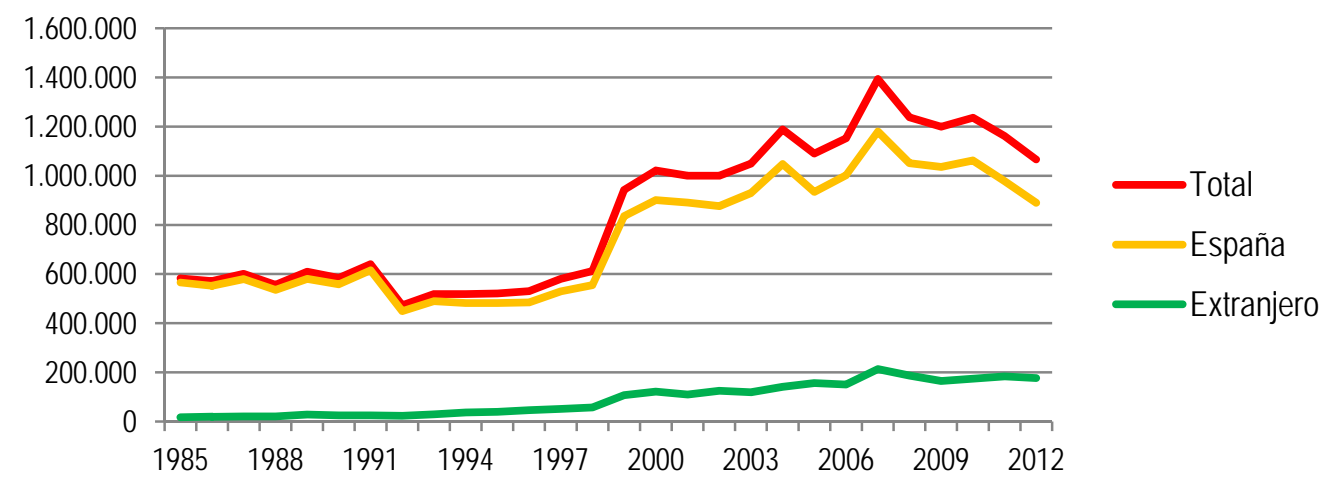

Fuente: Elaboración propia a partir de datos del INE (1986-2013).

En cuanto a las pernoctaciones del turismo interno, la distribución porcentual es similar a la del número de viajeros, siendo las principales comunidades autónomas emisoras Castilla y León, Madrid, Galicia y Asturias, que aportan actualmente el $67 \%$ del total.

\section{Gráfico 17}

Distribución porcentual de las pernoctaciones según la comunidad autónoma de origen (2003-2012)

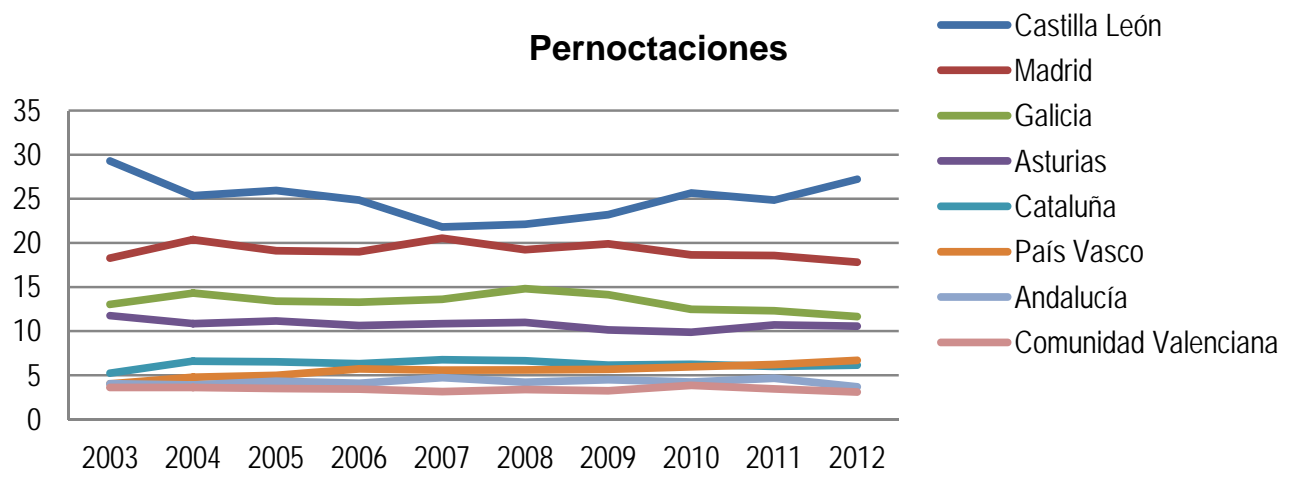

Fuente: Elaboración propia a partir de datos del INE (2004-2013). 
La evolución de los países de procedencia de los turistas sigue la misma tendencia que los viajeros. Desde 1985 hasta la actualidad los turistas que realizan un mayor volumen de pernoctaciones son alemanes seguidos a cierta distancia de ingleses, a partir de 1999 los ingleses son sustituidos por franceses. A continuación se sitúan portugueses e italianos. Concretamente en 2012, el ranking de país de procedencia de turistas es Alemania, Francia, EEUU e Italia.

\section{Gráfico 18}

Evolución del número de pernoctaciones de turistas extranjeros por nacionalidad (1985-2012)

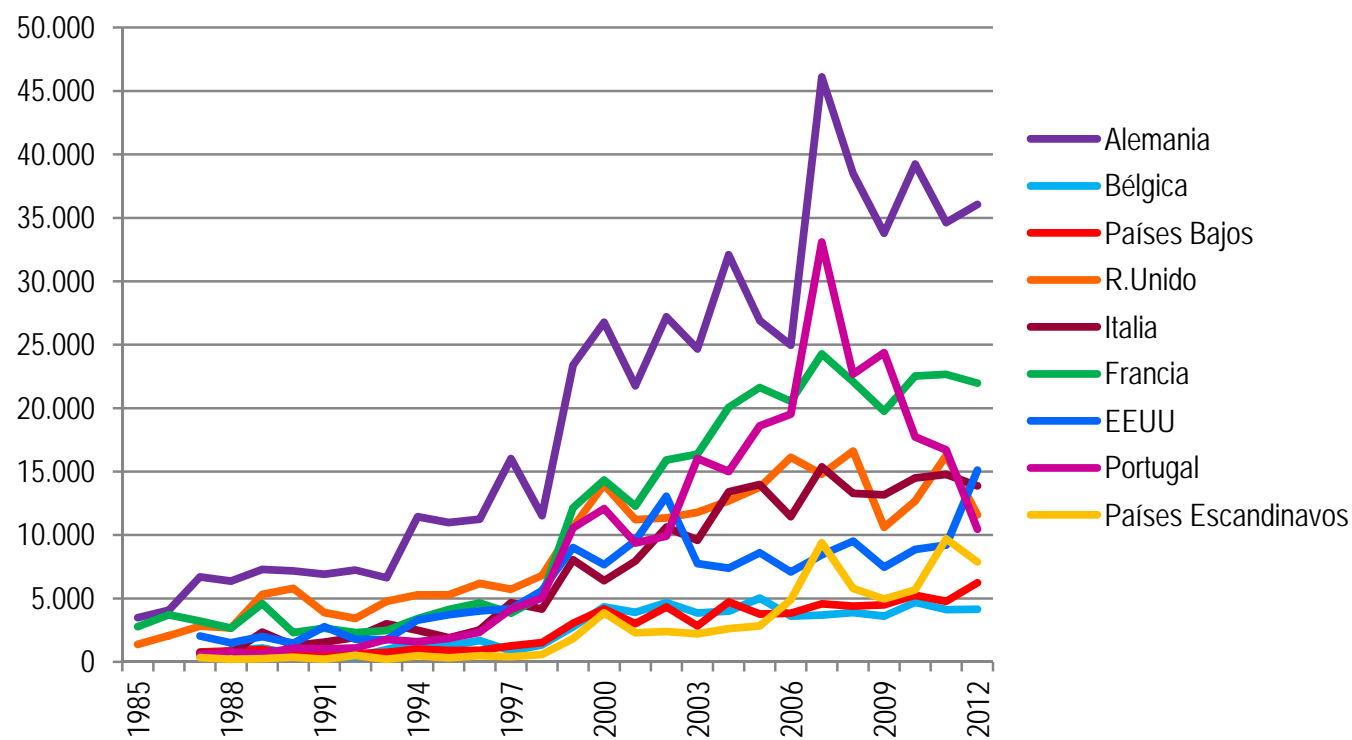

Fuente: Elaboración propia a partir de datos del INE (1986-2013).

El crecimiento del número de viajeros y de pernoctaciones en términos generales es constante hasta el año 2007, periodo álgido en el sector turístico a nivel nacional y también en esta provincia. A partir de dicho año desciende coincidiendo con los primeros efectos de la crisis.

Dicha evolución repercute en la estancia media de los turistas, el ratio más elevado se produce en 1985 con 1,85 días de estancia por turista, año a partir del cual empieza a descender hasta alcanzar la cota más baja en 1993 con 1,5 días de media. A partir de entonces cambia la tendencia subiendo a 1.64 días en 2012, sin embargo, no vuelve a alcanzar los parámetros del año 85.

La estancia media viene marcada principalmente por la evolución del turismo nacional, ya que el porcentaje de viajeros procedentes de España es sustancialmente superior al de extranjeros, de hecho su estancia media es siempre mayor aunque nunca supera 1,88 días (en 1985) ni es inferior a 1,5 (en 1992), actualmente es de 1,72 días. Respecto al turismo extranjero, en el 2007 alcanza su máxima cota, con 1,56 días, actualmente ha descendido situándose en 1,32 días. La diferencia entre el turismo de interior y el extranjero es significativa y en ninguno de los dos casos supera las dos noches. 


\section{Gráfico 19}

Evolución de la estancia media de los turistas (1999-2012)

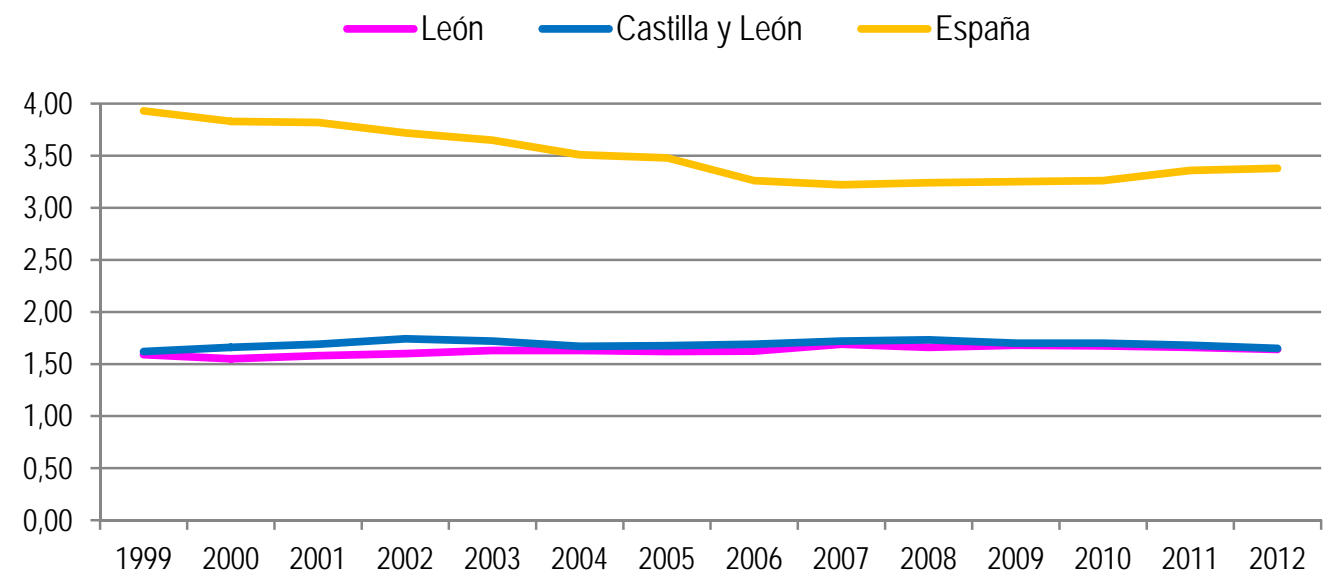

Fuente: Elaboración propia a partir de datos del INE (2000-2013).

Un análisis de la estancia media en función de país de procedencia de los turistas muestra que siempre es superior a un día y nunca alcanza los tres días, salvo coyunturalmente los escandinavos en el año 2007. Actualmente los portugueses son los únicos turistas que superan los dos días de estancia, de hecho es el país que presenta una mejor evolución respecto al turismo leonés. Estados Unidos y los países escandinavos superan el día y medio, mientras que franceses e italianos presentan la menor estancia media, en torno a 1,2 días.

\section{Sector tuństico de la ciudad de León}

\subsection{Oferta tuństica}

La capital de la provincia leonesa constituye el destino turístico más relevante de la región analizada, por este motivo se destina un apartado de este capítulo al análisis de la evolución del turismo a partir de 2003, año en el que el INE comienza a recoger datos estadís- ticos por puntos turísticos, entre los cuales se encuentra la ciudad de León.

Según los datos ofrecidos por la Encuesta de Ocupación Hotelera del INE, actualmente la capital leonesa cuenta con 56 establecimientos hoteleros que ofertan 3781 plazas. Este número de alojamientos representa el $21.54 \%$ del total de la provincia y el $4.28 \%$ de la comunidad autónoma. Respecto a las plazas, la ciudad de León posee el $36 \%$ de la provincia y el $6,67 \%$ de Castilla y León.

La evolución experimentada desde el año 2003 hasta el 2012 muestra que el número de establecimientos en la ciudad de León se ha incrementado un $30.23 \%$, porcentaje que alcanza el $35.67 \%$ si se hace referencia a las plazas. Comparando el crecimiento medio de este periodo de la oferta alojativa de la ciudad de León con los datos de la provincia, la comunidad autónoma y el conjunto del país; se puede observar que esta localidad ha experimentado un crecimiento medio sensiblemente superior a los demás, con cifras por encima del $3.2 \%$ en el caso de los establecimientos y superiores al $3,5 \%$ respecto a las plazas. 


\section{Gráfico 20}

Evolución de los alojamientos en la ciudad de León (2003-2012)
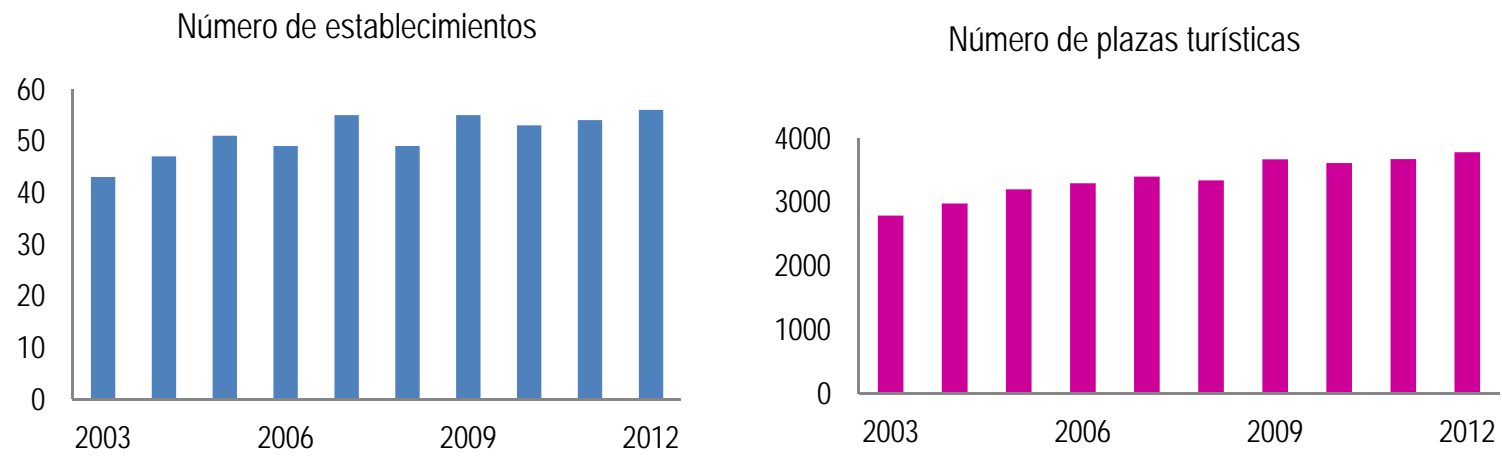

Fuente: Elaboración propia a partir de datos del INE (2004-2013).

En cuanto al empleo del sector turístico, el personal ocupado en establecimientos hoteleros en la ciudad de León mantiene en general una tendencia creciente desde 2003, pasando de una media anual de 366 personas en dicho año, a 471 en 2012. No obstante, entre los años 2010 y 2012 se observa una caída del 5\%.

\section{Gráfico 21}

Personal ocupado en establecimientos hoteleros en la ciudad de León (2003-2012)

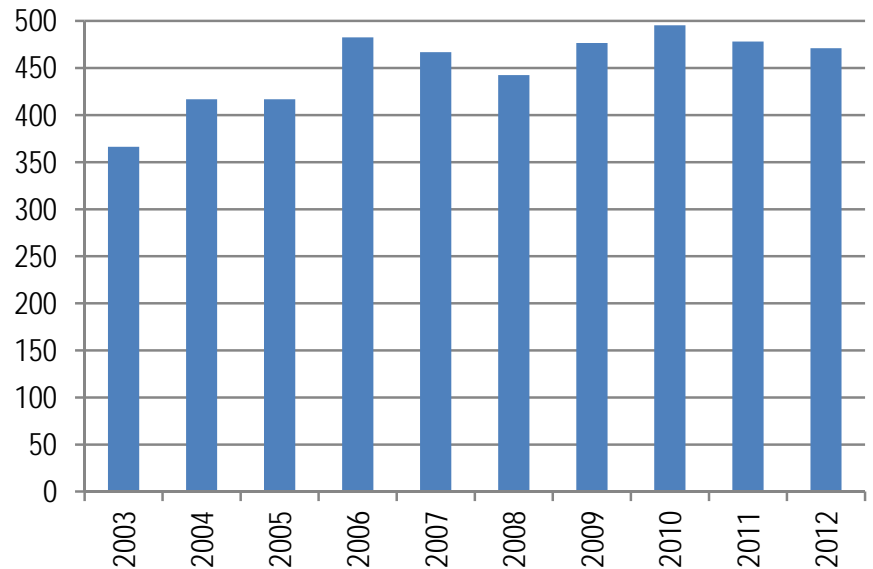

Fuente: Elaboración propia a partir de datos del INE (2004-2013).

La distribución de los establecimientos hoteleros en función de su categoría muestra, que el 75\% de las plazas hoteleras son de categoría media y superior, de 3 a 5 estrellas, sin embargo, respecto al número de establecimientos dichos porcentajes se invierten, es decir, existe en la ciudad un elevado volumen de establecimientos de categoría baja pero el número de plazas ofertadas es pequeño. 
El nivel de satisfacción de los turistas alojados en establecimientos reglados en la ciudad de León, época del año de mayor demanda turística en la ciudad, es notable alto, mostrando mayor grado de satisfacción con la atención recibida y el precio del alojamiento (Ayuntamiento de León ${ }^{3}$, 2011).

\section{Gráfico 22}

\section{Grado de satisfacción de la hotelería de la ciudad de León (verano)}

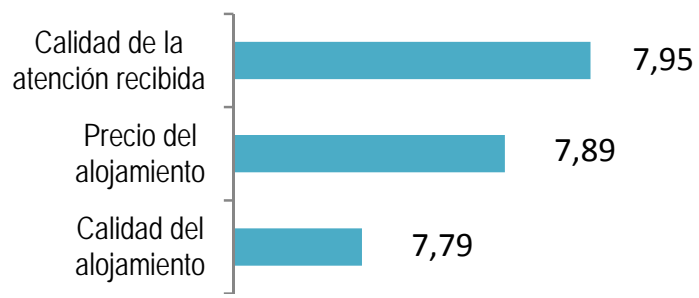

Base: 389 encuestados que pernoctaron en alojamientos reglados Fuente: Elaboración propia a partir de datos del Ayuntamiento de León (2011).

El turista que visita la ciudad de León durante el verano pone de manifiesto un elevado grado de satisfacción, especialmente respecto a la calidad de la comida (supera la puntuación de 8 sobre 10), aunque también sobre el propio restaurante, la calidad de la atención recibida y las instalaciones (con puntuaciones próximas a 8). Las comidas y bebidas típicas de León, que más gustan al viajero son las tapas leonesas, la cecina, el embutido, la morcilla y los vinos de denominación de origen tanto del Bierzo, como de Tierra de León (Ayuntamiento de León, 2011).

\footnotetext{
3 El Observatorio Turístico de la ciudad de León ha recogido datos desde julio de 2009 hasta septiembre de 2011, con la finalidad de profundizar en el conocimiento de los viajeros que visitan la ciudad y, consecuentemente, poder adaptar la oferta de la ciudad a sus necesidades y deseos mediante el diseño de productos turísticos acordes a sus expectativas. En la actualidad ya no existe.
}

\section{Gráfico 23}

Grado de satisfacción de la restauración de la ciudad de León verano

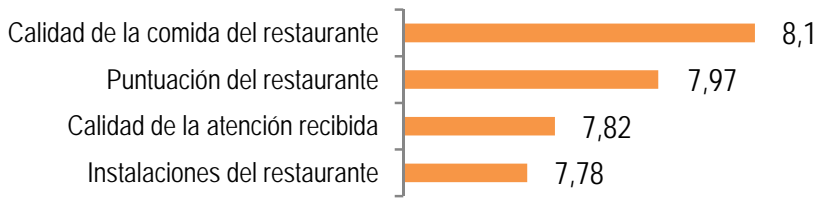

Base: 395 encuestados que contestaron a la pregunta.

Fuente: Elaboración propia a partir de datos del Ayuntamiento de León (2011).

\subsection{Demanda turística}

La evolución del número de turistas de la ciudad durante el periodo analizado 2003-2012 es positiva y prácticamente constante. El crecimiento de turistas que visitan la ciudad es el $3 \%$, porcentaje sustancialmente superior a los incrementos experimentados tanto por la provincia $(0.56 \%)$, como por la comunidad autónoma (0.95\%), aunque inferior al conjunto nacional (3.38\%). Todos ellos ligeramente inferiores a los experimentados en el año anterior.

En el año 2012 la ciudad de León recibe 349.190 turistas que realizan 581.661 pernoctaciones, lo que representa el $53.63 \%$ de los turistas de la provincia leonesa y cerca del $9 \%$ de los turistas de la comunidad autónoma de Castilla y León.

Aproximadamente el $78 \%$ de los turistas que visitan León en 2012 residen en España. Sin embargo, se observa que durante el periodo analizado ha crecido más el número de turistas extranjeros (6.59\% de incremento medio anual) que los nacionales (3\%). El incremento del número de extranjeros es superior al doble que el de la comunidad (2.89\%) y bastante mayor que el de España (4.64\%). 
Evolución del número de viajeros y pernoctaciones de los turistas de la ciudad de León (2003-2012)

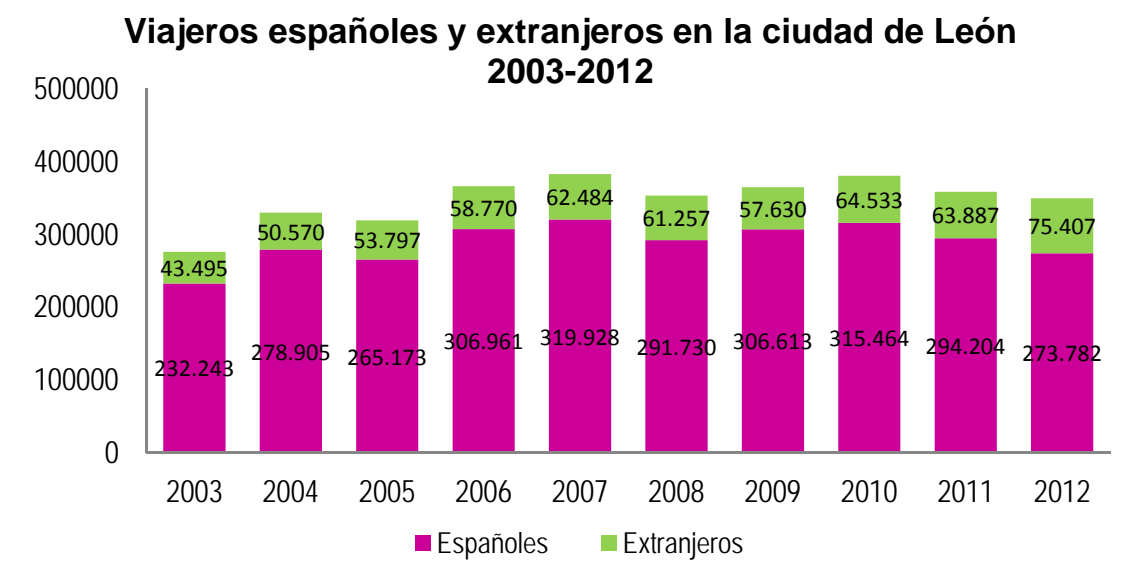

Pernoctaciones españoles y extranjeros 2003-2012

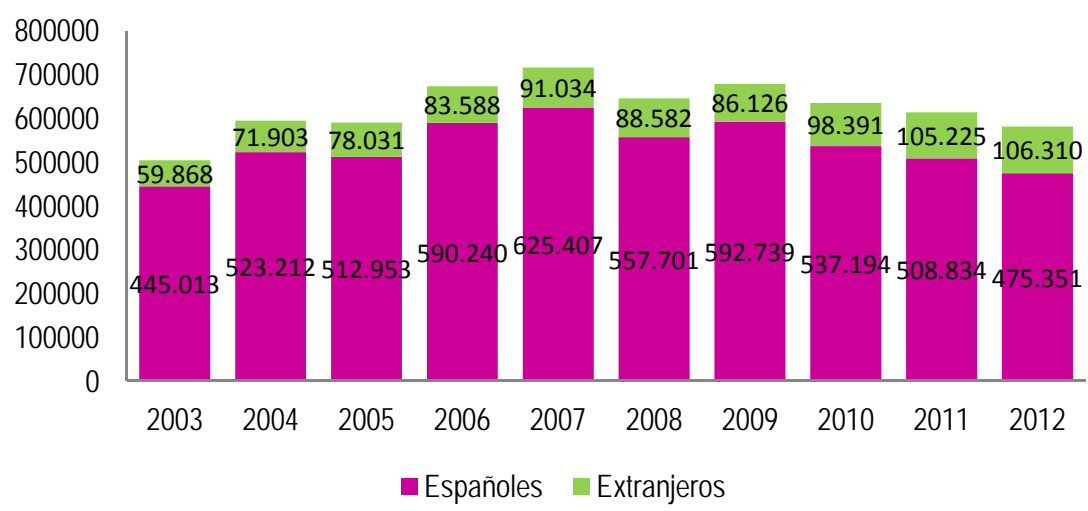

Incremento medio del número de visitantes 2003-2012

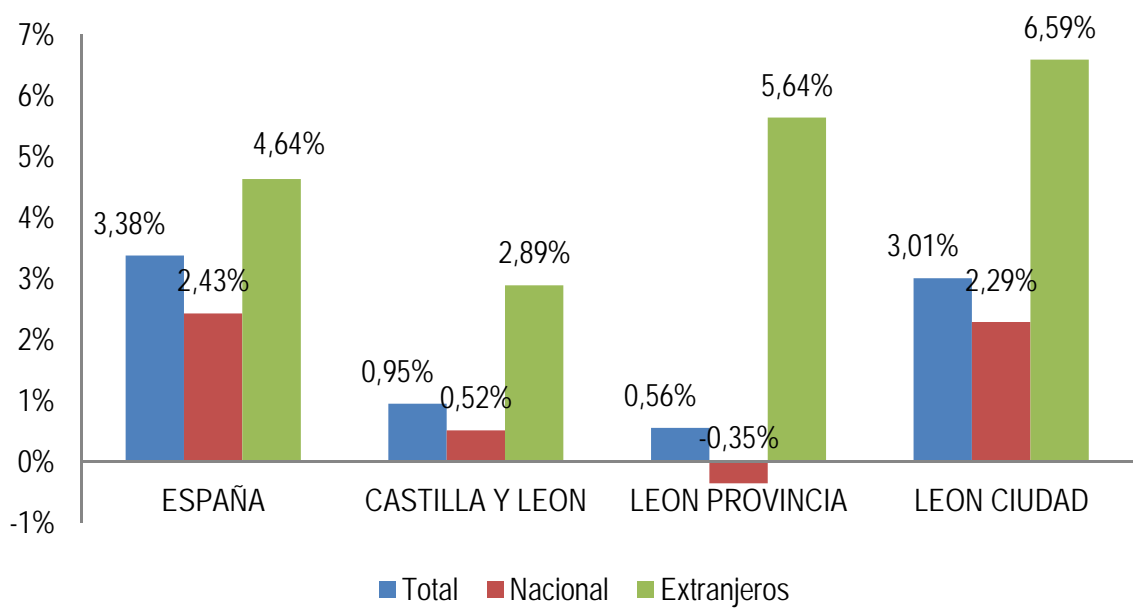

Fuente: Elaboración propia a partir de datos del INE (2004-2013). 
La estacionalidad turística de León capital no es muy elevada, ya que desde abril hasta octubre se observa un incremento constante de la llegada de turistas; no obstante, el mes álgido es agosto y en general la época estival.

\section{Gráfico 25}

\section{Estacionalidad turística de la ciudad de León}

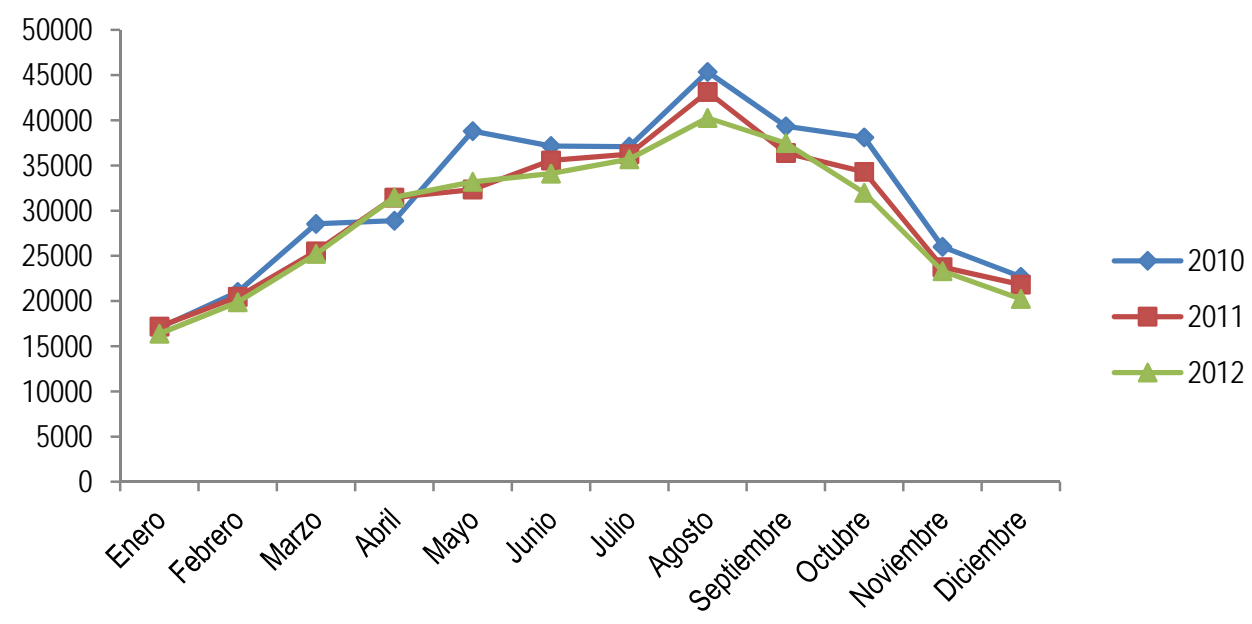

Fuente: Elaboración propia a partir de datos del INE (2013).

\subsection{Perfil sociodemográfico y hábitos comportamentales del turista de la ciudad de León}

\subsubsection{Descripción del turista estival}

El perfil del viajero estival ${ }^{4}$ de la ciudad de León es un turista español, entre 25 y 54 años, casado o soltero, con un nivel de estudios elevado, activo y con un nivel de ingresos medio.

Durante esta época del año realiza viajes de ocio, con la finalidad principal de hacer un recorrido turístico y se aloja una o dos noches en la ciudad de León, es decir, para León se trata principalmente de un turista de fin de semana.

\footnotetext{
4 El Observatorio Turístico de la Ciudad recoge información sobre los turistas que visitan León durante el periodo estival, mediante una encuesta personal realizada en puntos de interés turístico a personas mayores de 15 años que visitan la ciudad, tanto en días de diario como en fin de semana.
}

El motivo principal de viajar a León es visitar la ciudad, sus monumentos y de manera más específica, la Catedral de León. Existe, además, un porcentaje elevado que concretamente está realizando el Camino de Santiago. A continuación se posiciona el concepto de "estar de paso", conocer el arte y la historia de la ciudad, visitar a familiares y amigos, conocer nuevos lugares y la gastronomía.

El porcentaje de viajeros que señala León como destino principal de su viaje es considerablemente elevado, el $43,55 \%$.

La organización del viaje es mayoritariamente por cuenta propia, el 38\% afirma que busca información a través de internet especialmente sobre el alojamiento. Viajan acompañados por su pareja, con la familia o con amigos. Las modalidades de alojamiento más seleccionadas son los hoteles de 3 y 4 estrellas y el medio de transporte el vehículo propio. También existen peregrinos que han llegado a León a pie o en bicicleta. 
Entre los lugares visitados por los viajeros, la Catedral de León constituye el principal icono de la ciudad. A continuación se sitúa el Barrio Húmedo, zona que ha conseguido un alto posicionamiento de manera natural entre los turistas, seguido por La Real Colegiata de San Isidoro, el edificio Botines de Gaudí, la Plaza Mayor, el Hostal de San Marcos y el Barrio Romántico. Un tercer nivel viene marcado por el Palacio de los Guzmanes y otros lugares del Camino de Santiago.

Finalmente, cabe reseñar que el Musac, el Palacio Conde Luna, la visita diurna de las vidrieras de la Catedral, el Museo de León también constituyen lugares de interés para los turistas, aunque posiblemente todavía sean poco conocidos.

El nivel de satisfacción global de la visita de los viajeros estivales es sustancialmente elevado, de 8,43 sobre 10 .

\subsubsection{Descripción del turista del resto del año. Comparativa entre viajero de ocio y negocio}

El turista de otoño, invierno y primavera ${ }^{5}$ es diferente al viajero vacacional del verano.

El $28 \%$ de los viajeros analizados se desplazan por motivos de negocio o trabajo, el $23 \%$ realizan un viaje de fin de semana, el $18 \%$ por descanso vacacional y el $18 \%$ para realizar un recorrido turístico. Es importante resaltar que León constituye el destino principal para cerca del $80 \%$ de los viajeros que realizan viajes de negocios a esta ciudad, porcentaje que disminuye hasta el $59 \%$ en el caso de los turistas de ocio, aun así considerablemente elevado.

La forma de organizar los viajes es diferente dependiendo de la tipología del viaje. Los turistas de ocio suelen organizar los viajes por

5 El Observatorio Turístico de la Ciudad recoge información sobre los turistas que visitan León durante los meses de octubre a junio, mediante una encuesta personal realizada en establecimientos hoteleros de 3,4 y 5 estrellas de la ciudad a personas mayores de 15 años que pernoctan en la ciudad, tanto en días de diario como de fin de semana. su cuenta, al igual que ocurre en la época estival, sin embargo, en el caso de los viajeros de trabajo suelen ser sus empresas las encargadas de esta tarea. También varía el medio de transporte, incrementándose el avión para la tipología de negocios en detrimento del coche e incluso el tren, mientras que en la tipología de ocio se sigue empleando principalmente el vehículo propio.

El motivo de la visita a la ciudad de León de los viajeros de trabajo o negocios es único. En lo que respecta a los viajeros de ocio, su principal razón es visitar la ciudad y sus monumentos y más concretamente la catedral. Posteriormente se citan otros aspectos como ver a familiares y amigos, el arte y la historia de León, la gastronomía y el Camino de Santiago.

Los lugares visitados por ambas tipologías de turistas prácticamente coinciden tanto en orden como en porcentajes. La catedral sigue siendo el icono indiscutible de León que, junto con el Barrio Húmedo, constituyen las dos principales visitas de los viajeros, conformando de por sí un producto turístico de la ciudad. A continuación el Hostal de San Marcos y la Basílica de San Isidoro también se posicionan en un lugar destacado, siendo esta última más visitada por los viajeros de ocio que por los de negocio. El Barrio Romántico está adquiriendo cada vez mayor relevancia, aunque todavía no es tan conocido como el Barrio Húmedo.

El nivel de satisfacción global de los turistas que visitan la ciudad de León, es en términos generales considerablemente elevado. La satisfacción es superior en el caso de los viajeros que visitan la ciudad por motivos de ocio $(8,4)$ frente a los de negocio $(7,7)$, posiblemente porque su objetivo principal es conocer la ciudad y disponen de más tiempo para ello.

\subsection{Competitividad tuństica}

La importancia del turismo urbano en el sector turístico español es cada vez mayor, por ello, Exceltur ha realizado recientemente un informe denominado 'UrbanTur 2012: Monitor de Competitividad Turística de los destinos urbanos españoles', donde valora veinte 
ciudades: Barcelona, Madrid, Valencia, Sevilla, San Sebastián, Málaga, Bilbao, Santiago, Zaragoza, Granada, Salamanca, Gijón, Córdoba, A Coruña, Alicante, Santander, Toledo, Oviedo, Burgos y León, siendo ésta última la segunda ciudad más pequeña en población incluida en el estudio (EXCELTUR, 2013).

La primera lectura que se puede hacer sobre dicho informe, es que León está siendo considerado como uno de los veinte destinos urbanos más atractivos del país, aspecto realmente positivo y esperanzador desde el punto de vista del potencial turístico de esta ciudad. No obstante, le queda un importante camino por recorrer ya que la media global de valoración sitúa León al final de la lista.

El informe analiza cincuenta y siete indicadores con la finalidad de determinar la evolución de la capacidad competitiva en los mercados turísticos de cada una de las ciudades. Dichos indicadores se agrupan en seis pilares: capacidad de atracción de la oferta de productos de ocio, capacidad de atracción de la oferta de productos turísticos de negocios, condicionantes competitivos del entorno urbano y de la vida local, accesibilidad y movilidad, gobernanza y gestión estratégica y, finalmente, desempeño resultados económicos y sociales. Todos ellos ponen en evidencia la necesidad de mejora del sector turístico leonés.

Las principales fortalezas competitivas de León frente al resto de ciudades, de los cincuenta y siete indicadores analizados, son la dotación de zonas verdes (segunda posición), la disponibilidad de un servicio público de bicicletas para turistas (primera posición), la agilidad en la gestión administrativa (quinta posición) y la estacionalidad (tercera posición).

León obtiene una posición competitiva entre las diez primeras ciudades en otros aspectos como la cualificación de espacios públicos para el turismo, el turismo de grandes eventos musicales, la calidad el aire, la frecuencia de trenes de alta gama, la conectividad ferroviaria de alta velocidad, la información en varios idiomas en el transporte público, la posición del turismo en la escala organizativa municipal, la apuesta institucional por la coordinación interconcejalías, el desarrollo de acciones de marketing en plataformas multimedia y el desarrollo de aplicaciones móviles de información y disfrute turístico de la ciudad, sin embargo, las puntuaciones obtenidas son considerablemente bajas, por lo que el informe habla de debilidades competitivas.

Los treinta y seis indicadores restantes obtienen una puntuación inferior a la media.

León muestra diferentes posicionamientos en función de las distintas tipologías de turismo de ocio. Según el citado informe, el turismo de grandes eventos musicales ocupa la posición octava, el turismo familiar la quince, el gastronómico la dieciséis, el idiomático la diecisiete y el turismo de shopping la penúltima posición.

Como conclusión se puede afirmar que la ciudad de León es indiscutiblemente un destino urbano con gran potencial, no obstante, tienen un importante desafío, trabajar sus diversas líneas de producto y mejorar su imagen, con la finalidad de alcanzar un fuerte posicionamiento competitivo.

\section{Política tuństica}

La Política Turística es el conjunto de acciones desarrolladas por las Administraciones Públicas destinadas a orientar, regular, fomentar $y$ proteger la actividad turística, traduciéndose en planes y programas de desarrollo sectorial.

La competencia turística se encuentra distribuida en los distintos niveles de administración pública que consagra la Constitución de 1978: la administración central, la administración autonómica y la administración local (López Palomeque, 2004). Por tanto, para comprender la intervención de la Administración Pública Local, es necesario realizar una revisión de las políticas centrales y autonómicas.

A nivel nacional la Administración Central he elaborado el Plan de Turismo Español Horizonte 2020 cuyo desarrollo es del 2008 al 2012, vertebrado en cinco ejes prioritarios: el desarrollo de una nueva economía turística fundamentada en el conocimiento y la innovación, 
el valor del cliente, la sostenibilidad, el entorno competitivo y el liderazgo compartido. A partir de dicho plan se han desarrollado planes estratégicos en las diferentes comunidades autónomas (Tourspain, 2007).

En Castilla y León, se ha desarrollado y está prácticamente llegando a su fin el Plan Estratégico de Turismo de Castilla y León 20092013 cuyo principal objetivo es mejorar la posición competitiva de la comunidad como destino turístico mediante una estrategia de diferenciación (Junta de Castilla y León, 2009). Una vez finalizado dicho Plan se ejecutará el II Plan Estratégico de Turismo de Castilla y León 2014-2018, pendiente de aprobación, cuyos objetivos prioritarios son: fortalecer el tejido empresarial turístico de Castilla y León, avanzar en la profesionalización de los recursos humanos y en la gestión del conocimiento turístico; rentabilizar las infraestructuras turísticas de la comunidad para crear una oferta turística competitiva que ponga al sector turístico al servicio de la cohesión territorial; potenciar la competitividad a través de la innovación y la calidad; y fortalecer la presencia de Castilla y León en los mercados turísticos a través de la promoción y la comercialización, con especial incidencia en la internacionalización de la oferta. De hecho, ya se ha presentado el Plan de Marketing Turístico 2013-2014 cuya finalidad es promocionar y consolidar el posicionamiento nacional e internacional de Castilla y León. Su eje vertebrador es enfatizar que se trata de una región con identidad propia con una oferta de ocio completa y variada. Un destino con un atractivo permanente que ofrece múltiples y variadas experiencias, de ahí su nueva campaña: "El museo más grande del mundo".

León en este contexto se encuentra en una buena posición, aunque actualmente no cuenta con ningún Plan Integral Turístico, ya que dispone de numerosos y variados recursos que bien definidos y potenciados como productos y dirigidos a los públicos objetivo adecuados, pueden posicionar la provincia con una oferta diferenciada y de calidad. Destaca dentro del Plan Estratégico de Turismo de Castilla y León 2009-2013 en la oferta de turismo cultural, de turismo rural y activo y dispone, además, de Grandes Rutas como el Camino de Santiago y la Ruta o Vía de la Plata que debe consolidar con estándares de excelencia. Por otra parte, está en disposición de impulsar productos turísticos con gran potencial como el turismo gastronómico, enológico e idiomático e, incluso, generar nuevos productos todavía emergentes como el turismo micológico y el ornitológico, todos ellos se sitúan dentro de las propuestas a impulsar por el citado Plan Estratégico.

\section{Conc lusiones}

Los cambios experimentados por la demanda turística de los años ochenta provocan el surgimiento de un viajero bien informado, experimentado y maduro que solicita ofertas diferentes al turismo de sol y playa, lo que estimula el desarrollo de modalidades turísticas como el turismo cultural, urbano, rural, entre otras. Esta tendencia favorece la desconcentración en el turismo español y, consecuentemente, potencia el desarrollo de dicha actividad en regiones de interior como León.

La década de los noventa llega a nivel nacional con el Plan Marco de Competitividad del Turismo Español (Plan FUTURES) que trata de impulsar el desarrollo global del turismo español mediante el consenso de las políticas turísticas de las diferentes comunidades autónomas. Y el nuevo milenio enfoca sus estrategias hacia la mejora de la calidad del sector mediante el Plan Integral de Calidad de Turismo Español (PICTE).

En la actualidad se están ejecutando planes estratégicos en diferentes comunidades autónomas conforme al Plan de Turismo Español Horizonte 2020. Así se han definido las bases del vigente Plan Estratégico de Turismo de Castilla y León 2009-2013, cuyo principal objetivo es mejorar la posición competitiva de dicha comunidad autónoma como destino turístico mediante una estrategia de diferenciación y se está diseñando el II Plan Estratégico de Turismo de Castilla y León 20142018 que se ejecutará a continuación.

En este contexto, con la finalidad de evaluar el posicionamiento ocupado por León se debe analizar la evolución del mercado turístico en la 
provincia a lo largo de las últimas décadas, tanto de la oferta, como de la demanda.

La oferta turística abarca un conjunto considerablemente amplio de subsectores, tales como el alojamiento, transporte, restauración, empresas de intermediación así como de actividades complementarias. Revisados los datos disponibles a este respecto y centrándose en la oferta de alojamientos, se puede observar que León ha apostado por la calidad, ya que son las modalidades alojativas de categoría media y alta las que mejor evolucionan a lo largo del periodo analizado y las que disponen de más personal, concretamente en 2012 el sesenta por ciento del total. A pesar de ello, el grado de ocupación del conjunto de la hostelería durante este periodo es ligeramente inferior al de Castilla y León y sustancialmente menor que el español.

Dentro del conjunto de la oferta de alojamiento es necesario realizar una mención especial al turismo rural, ya que a pesar de su relativa reciente aparición ha llegado a alcanzar un posicionamiento destacado respecto al conjunto de la oferta de la comunidad e incluso a nivel nacional.

Otra industria propiamente turística viene configurada por el sector de intermedación. A este respecto, el volumen de empresas de distribución ha crecido también sustancialmente, ya que en 1987 era prácticamente inexistente mientras que en la actualidad más de cien empresas ofertan sus servicios, de las cuáles la mayoría son minoristas aunque también hay mayoristas-minoristas. El porcentaje que representan las empresas de distribución on-line es meramente anecdótico.

Por último, la restauración ha experimentado una evolución positiva constante a lo largo de todo el periodo, tanto en restaurantes como en cafeterías.

Respecto a la oferta turística de la ciudad de León, el volumen de alojamientos representa en la actualidad cerca de la cuarta parte del total de la provincia y más del cuatro por ciento del conjunto de la comunidad autónoma. En relación con las plazas, el porcentaje es superior a la tercera parte del total de la oferta de la provincia y próxima al siete por ciento de Castilla y León. El crecimiento medio experimentado por esta localidad desde 2003, año en el que se comienza a disponer de datos, hasta 2012, es sensiblemente superior al de la provincia, la comunidad y al nacional. El nivel de satisfacción de los turistas alojados en hotelería en la ciudad de León es notable alto.

El otro polo del mercado, el de la demanda turística, ha evolucionado positivamente durante las tres décadas analizadas, con un incremento medio interanual del tres y medio por ciento. Dicha tendencia se debe tanto a las visitas recibidas por los turistas nacionales como extranjeros, aunque es sustancialmente más abundante el turismo de interior. El incremento interanual medio de los turistas extranjeros en la provincia es considerablemente elevado, superior al diez por ciento, esto se debe principalmente a que en los años ochenta apenas se podía considerar León como un destino para el turismo exterior, mientras que en la actualidad ha alcanzado cierto nivel de notoriedad.

La procedencia del turismo internacional es desde 1985 mayoritariamente europea. Alemania es el principal país emisor de turistas hacia la provincia de León seguido, aunque a considerable distancia de Francia y durante la última década de Portugal e Italia, concretamente en 2012 Portugal ha sido sustituido por EEUU. No obstante, ni españoles ni extranjeros superan los dos días de estancia media.

Del conjunto de la provincia, la capital es el destino más visitado por los turistas. La evolución del número de turistas durante el periodo analizado 2003-2012 es positiva y prácticamente constante, siendo su crecimiento del tres por ciento. Además la estacionalidad turística de la capital no es muy elevada, ya que desde abril hasta octubre se observa un incremento constante de llegada de turistas, aunque el mes álgido es agosto.

El perfil del viajero de la ciudad es un turista español, entre 25 y 54 años, casado o soltero, con un elevado nivel de estudios, activo y de ingresos medios. El tipo de viaje que realiza durante el verano es principalmente de ocio, 
mientras que el resto del año se desplaza además por negocios o trabajo.

El motivo principal de viajar a León para los viajeros estivales es visitar la ciudad, sus monumentos y de manera más específica la Catedral de León, así como realizar el Camino de Santiago. Respecto a los turistas del resto del año, en el caso de los viajeros de negocios, éstos constituyen su razón fundamental, mientras que para los viajeros de ocio, las motivaciones son muy similares a las del verano.

El interés turístico que suscita la ciudad viene refrendado por el informe "UrbanTur 2012" recientemente realizado por Exceltur, ya que selecciona la capital leonesa como uno de los veinte destinos urbanos más atractivos del país. Este aspecto es realmente positivo y esperanzador desde el punto de vista del potencial de la ciudad. No obstante, de los cincuenta y siete indicadores analizados en el estudio sólo destacan como fortalezas competitivas de León cuatro, la dotación de zonas verdes, la disponibilidad de un servicio público de bicicletas para turistas, la agilidad en la gestión administrativa y la estacionalidad. De hecho, la valoración media global sitúa León al final de la lista, por lo que debe de mejorar numerosos aspectos.

En su conjunto, el turismo de la provincia leonesa tiene un gran atractivo para diferentes segmentos de mercado, sin embargo, es una región relativamente poco conocida, por lo que debe de llevar a cabo un conjunto de medidas que le permitan posicionarse en un lugar destacado dentro del país. En primer lugar, debe generar y gestionar conocimiento de mercado con la finalidad de conocer al turista actual y analizar las tendencias futuras de su comportamiento. Esta primera medida le permitirá crear y desarrollar nuevos productos y servicios turísticos enfocados a los segmentos de mercado interesados por las modalidades turísticas en las que esta provincia puede destacar, como son el turismo cultural, rural, idiomático, enogastronómico, religioso, congresual, ornitológico y micológico. Para ello, ha de tener en cuenta tanto los elementos tangibles como intangibles que configuran su identidad, reforzar su singularidad y diferenciarse de las regiones competidoras.

Por otra parte, es fundamental que trabaje y gestione su propio valor de marca, además de aprovechar las ventajas de estar englobado en otras marcas paraguas de elevada notoriedad como es el Camino de Santiago e incluso Castilla y León.

Finalmente, debería realizar intensas campañas de promoción que permitan reforzar su imagen y alcanzar mayor notoriedad de la marca León como destino turístico.

\section{Referencias}

Ayuntamiento de León (2011). Boletín nº 1 y 2 del Observatorio Turístico de la Ciudad de León. Concejalía Turística del Ayuntamiento de León y Sociedad Mixta de León.

EXCELTUR (2013). Monitor de competitividad turística de los destinos urbanos españoles. UrbanTur2012. www.exceltur.org/excel01/contenido/portal/files/informe_urbatur2012.pdf.

Figuerola Palomo, M. (2013). Principales magnitudes. En J.I. Pulido Fernández (Dir.). La actividad turística española en 2012. Madrid: Ed. Universitaria Ramón Areces.

González Fernández, A.M., Rodríguez Santos, C. y Pertejo Blanco, A.R. (2012). Coyuntura de las Comunidades Autónomas: Castilla y León. En D. López Olivares y J.I. Pulido Fernández (Dir.). La actividad turística española en 2011 (pp. 255-264). Madrid: Ed. Universitaria Ramón Areces.

IET. Instituto de Estudios Turísticos (2013). Balance del turismo. Resultados de la actividad turística en España. Año 2012. Madrid: Ministerio de Industria, Comercio y Turismo. Secretaría de Estado de Turismo. 
IET. Instituto de Estudios Turísticos (2012). Plan Nacional e Integral de Turismo (PNIT) 2012-2015. Madrid: Ministerio de Industria, Comercio y Turismo. Secretaría de Estado de Turismo.

INE. Instituto Nacional de Estadística (1986-2013). Encuesta de ocupación en alojamientos de turismo rural. Madrid.

INE. Instituto Nacional de Estadística (1986-2013). Encuesta de ocupación en apartamentos turísticos. Madrid.

INE. Instituto Nacional de Estadística (1986-2013). Encuesta de ocupación en campings. Madrid.

INE. Instituto Nacional de Estadística (1986-2013). Encuesta de ocupación hotelera. Madrid.

Junta de Castilla y León (1986-2013). Anuario estadístico de Castilla y León. Valladolid: Dirección General de Estadística.

Junta de Castilla y León (2009). Plan estratégico de turismo de Castilla y León. Valladolid: Consejería de Cultura y Turismo. Dirección General de Turismo. www.turismodecastillayleon.com/cm/turcyl.

López Palomeque, F. (2004). La gestión pública del turismo en Cataluña. Organización y política turística de la administración autonómica. Investigaciones Geográficas, (34), 5-28.

Tourspain (2007). Turismo 2020. Plan de Turismo Español Horizonte 2020. Madrid. 